\title{
Identification of Early Behavioral Markers of Anxiety and Social Withdrawal in Preschool Children
}

Chelsea M. Ale

West Virginia University

Follow this and additional works at: https://researchrepository.wvu.edu/etd

\section{Recommended Citation}

Ale, Chelsea M., "Identification of Early Behavioral Markers of Anxiety and Social Withdrawal in Preschool Children" (2012). Graduate Theses, Dissertations, and Problem Reports. 447.

https://researchrepository.wvu.edu/etd/447

This Dissertation is protected by copyright and/or related rights. It has been brought to you by the The Research Repository @ WVU with permission from the rights-holder(s). You are free to use this Dissertation in any way that is permitted by the copyright and related rights legislation that applies to your use. For other uses you must obtain permission from the rights-holder(s) directly, unless additional rights are indicated by a Creative Commons license in the record and/ or on the work itself. This Dissertation has been accepted for inclusion in WVU Graduate Theses, Dissertations, and Problem Reports collection by an authorized administrator of The Research Repository @ WVU.

For more information, please contact researchrepository@mail.wvu.edu. 


\begin{abstract}
Identification of Early Behavioral Markers of Anxiety and Social Withdrawal in Preschool Children
\end{abstract}

\author{
Chelsea M. Ale, M.S.
}

Dissertation submitted to the Eberly College of Arts and Sciences at West Virginia University

in partial fulfillment of the requirements

for the degree of

Doctorate of Philosophy

in

Psychology

Tracy L. Morris, Ph.D., Chair

Elisa Krackow, Ph.D.

Kevin T. Larkin, Ph.D.

Michael Perone, Ph.D.

Amy E. Root, Ph.D.

Department of Psychology

Morgantown, West Virginia

2012

Keywords: Early Identification; Preschool; Observational Assessment; Shyness 


\section{Abstract \\ Identification of Early Behavioral Markers of Anxiety and Social Withdrawal \\ in Preschool Children \\ Chelsea M. Ale, M.S.}

This study examined an observational method for identifying specific behaviors to indicate social anxiety and social withdrawal in preschool children. During an interaction task with a novel adult, 28 children (ages 4 and 5) were observed for specific verbal and non-verbal behaviors (i.e., total utterances, commands, questions, unsolicited conversation, direct responses, eye gaze aversion, non-verbal response, physical distancing, freezing, smiling) and global behaviors (i.e., shyness, volume or speech, and postural rigidity), theoretically relevant to early childhood social anxiety. Behaviors observed during the interaction task were examined in relation to the parent-reported Spence Preschool Anxiety Scale's social anxiety subscale (Spence, Rapee, Edwards, \& Ingram, 2001) and the percentage of solitary behavior observed during unstructured play at preschool (Morris, Messer, \& Gross, 1995). Four years later, participants were re-contacted and 15 parents and children completed the Social Phobia and Anxiety Inventory for Children, Parent Report (P-SPAIC; Beidel, Turner, Hamlin, \& Morris, 2000), the Child Behavior Checklist Social Competence Subscale (CBCL, Social Competence; Achenbach, 1991), and the Social Phobia and Anxiety Inventory for Children, Item 10 self-report (SPAIC-10, T. Morris, personal communication). Preliminary analyses revealed that the specific verbal and non-verbal behaviors (with the exception of physical distancing and commands) were significantly correlated with the global behaviors. The global behaviors did not predict a significant amount of variance in solitary behavior during unstructured play. None of the specific verbal or non-verbal behaviors were significantly related to solitary behavior during unstructured play or the Spence Preschool Anxiety Scale's social anxiety subscale. Although solitary behavior during unstructured play and the Spence Preschool Anxiety Scale's social anxiety subscale were significantly related, neither one was significantly differentially related to any of 
the specific verbal or non-verbal behaviors observed during the interaction task. Unsolicited conversation and direct responses were significantly related to CBCL Social Competence at follow-up. Although a significant difference was not detected, a large effect was seen for total utterances, commands, and non-verbal responses to direct questions for those children who were elevated on one or more of the follow-up measures compared to children who were not elevated on any follow-up measure. Although limited by a lack of adequate statistical power and a restricted range of social anxiety at baseline, the study has important implications for the identification of specific behaviors in preschool that may be risk-factors for social anxiety childhood. 


\section{Acknowledgements}

I would like to thank my mentor, Dr. Tracy Morris, for her support throughout the years. Always a behaviorist, Tracy has shaped me into the academician that I have always aspired to become. I would also like to thank my dissertation committee members for their valuable comments and guidance throughout this project.

Lastly, I would like to thank my parents, sister, and friends for their unwavering encouragement and support. Even when I floundered, they knew I would not founder. 


\section{Table of Contents}

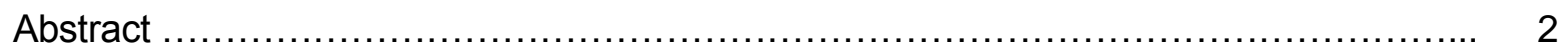

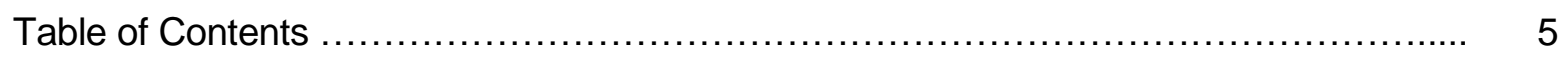

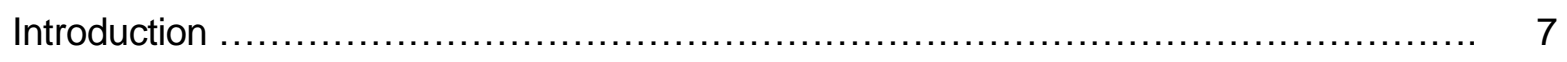

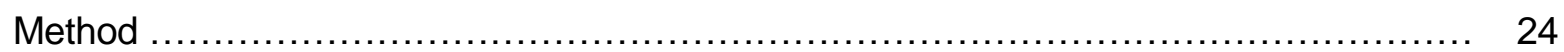

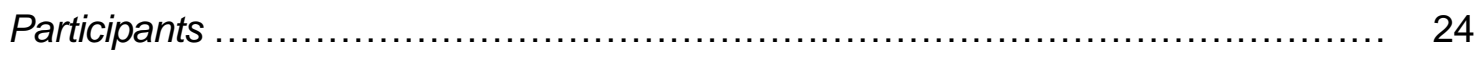

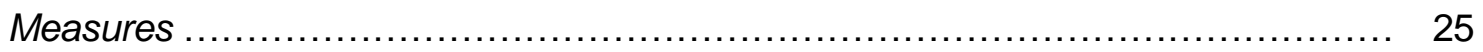

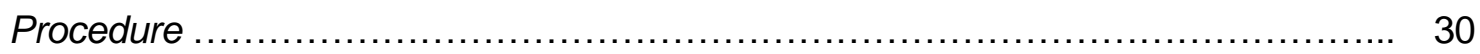

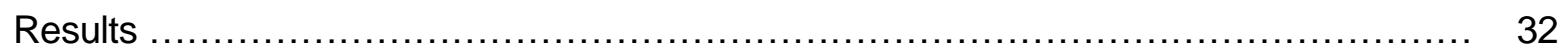

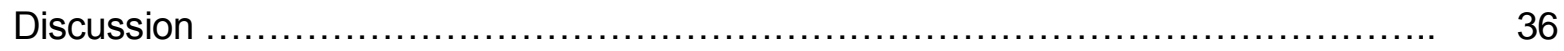

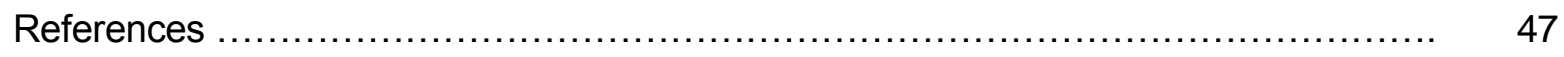

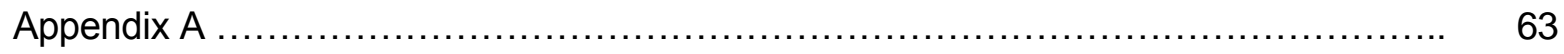

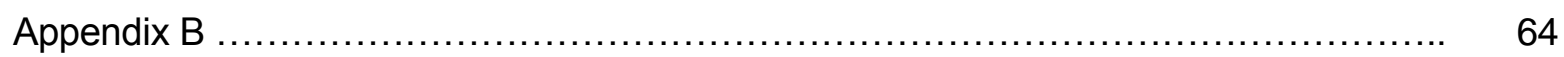

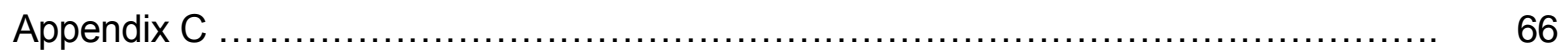




\section{List of Tables}

Table 1. Descriptives for Preschool-aged Assessments \& Follow-up Assessments.......... 57

Table 2. Correlations of Preschool Observational Codes............................... 58

Table 3. Regression Analysis Summary for Global Behavior Observations and Solitary

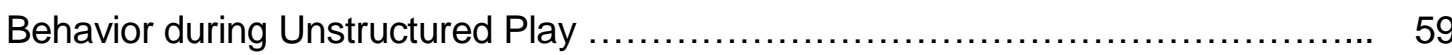

Table 4. Correlations of Preschool Micro-codes and Tests of Dependent Correlations among Preschool Other Informant Assessments..................................... 60

Table 5. Correlations between Preschool Observational Micro-codes and Follow-up

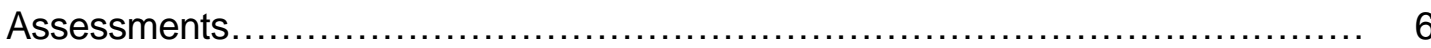

Table 6. Results of ANOVA tests comparing Preschool Observational Micro-codes for Children with and without Elevated Social Anxiety at Follow-up. 


\section{Identification of Behavioral Markers of Anxiety and Social Withdrawal in Preschool Children}

Social anxiety disorder is defined as excessive and persistent fear of social situations and unfamiliar people that causes significant avoidance and impairment in functioning (American Psychiatric Association, 2000). Epidemiological data suggest that social anxiety disorder affects 0.3 to $1 \%$ of children in any 3 month period and reaches highest prevalence of diagnosis by age 13 (Costello, Mustillo, Erkanli, Keeler, \& Angold, 2003). Internalizing symptoms, such as social anxiety, at ages 2 and 3 have been related to an almost 3 times greater risk of having anxiety or depression by age 10 or 11 (Mesman \& Koot, 2001). Even at subclinical levels, social anxiety may impede young children's typical social development (e.g., Asendorpf, Denissen, \& van Aken, 2008). Thus, identifying specific behaviors to recognize children who may be at risk for developing anxiety early-on may enable interventions to prevent impairment and promote typical behavior development.

In order to intervene early and understand which early behaviors may relate to later anxiety disorders, researchers have examined biologically-based and environmental variables that relate to maladaptive behavior development. A diathesis-stress model has been proposed to explain the development of anxiety, such that children with biological vulnerability who experience environmental stressors are more likely to experience impairment than those who only have vulnerability or who only experience environmental stressors (Gazelle \& Ladd, 2003; Schmidt, Polak, \& Spooner, 2005). Specifically, temperamental shyness (i.e., the diathesis) may be exacerbated due to specific social stressors (i.e. the environmental stress; Turner, Beidel, \& Wolff, 1991). Empirical studies have supported the diathesis-stress model of anxiety development. For example, Brozina and Abel (2006) observed 3rd graders who reported high levels of constructs previously related to anxious behaviors (i.e., shyness and behavioral inhibition) and found that those children who reported interpersonal and environmental stressors had significantly higher levels of anxiety by the 6th grade than their inhibited peers with few 
social stressors. Due to the interactive nature of anxiety development, it is important to examine both temperamental variables (e.g., behavioral inhibition and shyness) and interpersonal and environmental factors (e.g., social withdrawal). Children likely maintain a shy, inhibited developmental trajectory due to "cumulative continuity" (Caspi, Elder, \& Bem, 1988; Roberts \& Caspi, 2003). That is, environmental factors (e.g., peer influences, parents, teachers) shape the child's behavior (e.g., social withdrawal) and in-turn the child's behavior shapes the environment (e.g., peer rejection, parental involvement). This bi-directional cycle progresses over time to maintain and/or change the child's behavior. It is important to identify early behaviors which may set this course into action.

Given the chronic and debilitating nature of anxiety, it is important to identify early risk factors to aid in prevention and early intervention. First, early intervention is critical because maladaptive behaviors may not be as ingrained while children are young as in later childhood and adulthood. Hence, young children's behavior may be more amenable to change and may not require as much intervention to regain the typical developmental trajectory. Although the field of developmental psychopathology has made substantial gains in understanding the biological and environmental factors related to the development of anxiety, there remains a need for assessment tools of behavioral indicators of risk during preschool, an optimal period of intervention. Previous assessment methods have identified long term predictors of anxiety in infants (e.g., Hirshfeld-Becker, Biederman, Henin et al., 2007; Rimm-Kaufman \& Kagan, 2005; Schwartz, Reznick \& Kagan, 1999) and measures of pathological anxiety in early childhood (e.g., Glennon \& Weisz, 1978; Spence, Rapee, Edwards, \& Ingram, 2001), but neither of these approaches allow for an assessment tool to identify precursors to anxiety disorders during a period when children's social behavior can be readily modified.

Second, early intervention is critical because early anxious social withdrawal may lead to sustained peer rejection over the course of childhood (e.g., Gazelle, 2010). Children described by teachers as shy and fearful, initiate social contact less frequently, are reticent to interact with 
peers in unstructured play, and frequently are excluded by peers (Coplan, Prakash, O’Neil, \& Armer, 2004). Moreover, anxious social withdrawal and peer exclusion appear to be consistent both in school and outside of the school setting (Schneider, Younger, Smith, \& Freeman, 1998). Gazelle (2008) found that elementary school children who were identified as "anxious solitary" by their classmates, but who displayed normative levels of other behaviors, were rated by peers as less smart, less fun, and less likely to be a leader suggesting that they are more likely to be rejected by peers. In addition, children who experience both anxious social withdrawal and peer rejection are at the greatest risk of developing anxious and depressive symptoms by the middle childhood (Gazelle \& Ladd, 2003; Gazelle \& Rudolph, 2004), suggesting that anxious social withdrawal may be an early indicator of risk for internalizing mental health disorders.

Therefore the primary goal of the current study was to examine the utility of an analogue observational method that can be used with preschool children outside of the peer arena to identify those who display social withdrawal from peers. The second goal was to determine whether behaviors identified during preschool with this observational method related to social anxiety and social adjustment in elementary school.

\section{Early Identification}

Early identification screenings for academic difficulties and some developmental disorders are common practice during preschool (Conroy \& Brown, 2004; Denham, 2006a). The goals of early screenings are to identify children who may go on to develop problems later in life and to intervene before these children develop significant skill deficits (see Gredler, 1997). While early identification is very important for recognizing children who may experience significant anxiety and social impairment later in life, Gazelle and Ladd (2003) found that children who entered kindergarten displaying anxious, withdrawn behavior were already experiencing peer rejection, suggesting that assessment in elementary school may be too late. For these reasons, the preschool period may be an ideal time to identify risk factors for anxiety 
development due to the new opportunities to interact with peers and adults (Morris, HirshfeldBecker, Henin, \& Storch, 2004).

As noted above, measures of anxiety in preschool children do exist but there are limitations to these measures (e.g., inadequate consistency across reporters, lack of developmental sensitivity, and identifying broad constructs that are not readily applied to a child's behavior). Studies identifying these factors will now be reviewed.

Parent-report measures. Parental report of the child's anxiety is relied upon most frequently when assessing preschool-aged children. There have been many parent-report measures of child anxiety developed for school-aged children. Some measures assess a range of anxiety problems (e.g., Revised Child Anxiety and Depression Scale-Parent Report, the Spence Children's Anxiety Scale-Parent Report) and there are several parent-report measures which assess specific anxiety problems (e.g., the Social Phobia and Anxiety Inventory-Parent Report, the Fear Survey Schedule-Parent Report).

One continued problem with parent-report measures, even with school-aged children, is the lack of agreement between parent-report and child-report (e.g., Achenbach, McConaughy, \& Howell, 1987; Grills \& Ollendick, 2002). In a study of children 8- to 13-years-old, mothers rated their children as significantly more anxious than did fathers (Bögels \& Melick, 2004). Additionally, mother- and child-report were more congruent than father- and child-report of the child's anxiety symptoms. These findings raise important questions about the utility of parental report of child anxiety as a sole indicator of risk or current anxiety. In a study of preschool children and their parents, Edwards, Rapee, and Kennedy (2010) found that parental overprotection significantly predicted parent-report of child anxiety. This work has interesting implications for the contributions of parenting to the development of anxiety, but also brings to light an important consideration when relying on parent-report of child anxiety. It is unclear the extent to which children's anxiety affects parent-report and the extent to which parents' reports are influenced by their own anxiety (Edwards et al., 2010). Grills and Ollendick (2002) reviewed 
parent-child agreement on structured diagnostic interviews (i.e., specific questions asked to parents and children by a clinician) and concluded that parent-child agreement is less reliable for children with anxiety and depression (compared to children with externalizing behavior problems) and for younger children (compared to older children). When attempting to assess children who may develop anxiety, the variable validity of parent-report can become a significant barrier in early identification.

For young children, there are fewer options for parent-report measures. The Spence Preschool Anxiety Scale (Spence, Rapee, Edwards, \& Ingram, 2001) is one of the only measures that assesses anxiety specifically (i.e., social anxiety, separation anxiety, physical injury fears, generalized anxiety, and Obsessive-Compulsive Disorder type fears) for children ages 3 to 5. The Children's Moods, Fears, and Worries Questionnaire (Bayer, Sanson, \& Hemphill, 2006) is a recently developed parent-report measure for toddler anxiety and depression which has been tested in a sample of 2- to 4-year-old children.

Although these types of parent-report measures may provide important information, they should not be considered alone as indicative of clinically impairing behavior. As Morris, Hirshfeld-Becker, Henin, and Storch (2004) have noted, parent-report of a young child's anxious behavior also may be biased based on a parent's limited knowledge of developmental norms. Similarly, parents may not regularly observe their children in novel settings with peers and adults and may not appreciate the extent of their child's anxiety. A classic example of this crosssituational discontinuity is seen with children who are extremely shy at school, but may speak and play with comfort at home. Although anxiety is most commonly observed across situations, it remains unclear the extent to which parents may over-estimate or discount the impact of early childhood anxiety.

Observational assessments. Observational assessments have been the gold standard for assessing behavior problems in early childhood. However, surprisingly few observational measures have been validated for the assessment of early childhood anxiety. The 
Preschool Observational Scale of Anxiety (POSA; Glennon \& Weisz, 1978) is one of the rare measures of anxiety in young children. The POSA is an observational measure of separation anxiety developed in a sample of 2- to 5-year-old preschool children. This is one of the few studies which reports specific behavioral responses observed during an analogue task. While children were engaged in cognitive testing (digits, blocks, and sentences) with an adult over two sessions, the authors observed both verbal behavior (e.g., statement of desire to leave, physical complaint, and fear) and non-verbal behaviors (e.g., rigid posture, gratuitous movements, avoidance of eye contact). It is important to note that these children were observed within the first month of preschool. Participating children were separated from their parents for the first session during one of the first few days of school. The authors reported having observed significantly higher levels of anxiety in the first session than in the second, as might be expected during a transitional period. Specifically, lack of response to questions, touching mouth area, and posture also were significantly higher during the first session than the second session. Many of the observed behaviors were not calculated due to non-occurrence or very infrequent occurrence (e.g., statement of physical complaint or fear, scream, stutter). While the POSA provides important information for potential behavioral indicators of anxiety in preschool children, the authors did not report on the relation of each behavior to parent-report, but rather reported on the scale as a whole. The study also did not assess the relevance of the observations for social behavior (i.e., peer interactions).

While assessing parent-report of child anxiety disorders, Edwards, Rapee, Kennedy, and Spence (2010) rated how "anxious" children appeared during four novel tasks (i.e., interaction with a costumed stranger, going through an obstacle course, telling a short story, and singing a song). Observer-rated anxiety was significantly correlated with parent report of child anxiety across domains of fear (i.e., generalized anxiety, social anxiety, separation anxiety, and specific fears). Unfortunately, the authors did not report the levels of the individual behaviors researchers observed during each of the tasks. 
Self-Report. With older children and with adults, clinicians and researchers frequently rely on self-report of anxiety. While this method can provide insight into the individual's subjective experience, the utility of self-report for young children's anxiety remains questionable. For example, Perrin and Last (1992) compared the responses of boys with an anxiety disorder diagnosis to boys with an Attention-Deficit Hyperactivity Disorder diagnosis and boys with no psychiatric diagnosis on the Revised-Children's Manifest Anxiety Scale, the Modified State-Trait Anxiety Inventory for Children, and the Fear Survey Schedule-Revised. Using this self-report data, researchers were able to discriminate children in the diagnosed groups from the nodiagnosis group, but the authors reported no significant differences in self-reported behaviors in the Anxiety group and the ADHD group. Although there may be some degree of symptom overlap between anxiety and ADHD and these disorders may be co-occurring, the inability to differentiate these two groups exemplifies the lack of specificity in the self-report of anxiety for children.

Self-report measures assume the child's ability to reflect on and verbalize their physiological, emotional, and behavioral states. For young children especially, these demands may not be developmentally appropriate (e.g., Denham, 2006b). Although children develop emotional knowledge (i.e., recognizing emotional states and pairing feelings with situations) throughout the preschool period, Denham (2006a) reviewed a myriad of individual differences that may enhance or delay this skill development. With varying emotional knowledge, young children may not be able to reliably report on their internal states. Additionally, most preschoolaged children cannot read, so researchers and clinicians have employed more interactive methods for assessing young children (e.g., Pictorial Scale of Perceived Competence and Social Acceptance, Harter \& Pike, 1984; puppet vignettes for the assessment of emotion recognition, Denham, 1986). Even with creative self-report methods, children may have narrow or unreliable definitions of key vocabulary used during the assessment of anxiety (e.g., scared, afraid, shy). One study attempted to assess self-report of young children (32- to 59-months-old) 
by showing pictures of children with different degrees of emotions from "not scared at all" to "very, very scared" and asking the child which picture looks like them in a scary situation (Glennon \& Weisz, 1978). They found no significant correlation of child self-report with parentreport of the child, teacher-report of the child, or observational assessment (Glennon \& Weisz, 1978).

\section{Measurement of Anxiety Risk-factors}

In addition to measures of current level of anxiety, researchers have begun to isolate behavioral constructs in infants, preschoolers, and school-aged children which predict the development of anxiety at later developmental periods. In infancy and toddlerhood, the term behavioral inhibition has been used to describe biologically-based reticent behavior in the context of both social and nonsocial stimuli (Garcia-Coll, Kagan, \& Reznick, 1984). By early childhood, shyness (i.e., inhibition specifically in a social context) appears to relate most specifically to the development of social anxiety in childhood and beyond (e.g., HirshfeldBecker, Biederman, Henin et al., 2007). Environmentally, anxious social withdrawal in early childhood and childhood may influence skills development and social anxiety development (e.g., Gazelle, 2010). Although behavioral inhibition, shyness, and anxious social withdrawal are all components of the anxious response, they may have unique associations with the generalization of anxiety, social impairment, and the child's developmental course.

Infant assessment of risk. Temperamental risk factors in infancy have been related to anxiety in early childhood, childhood, and adulthood (see Kagan, 1992 for review). Garcia-Coll, Kagan, and Reznick (1984) identified a subset of infants who experience increased arousal and avoidance which these researchers first labeled as behavioral inhibition to the unfamiliar.

Behavioral inhibition may be a good indicator of risk because it has been shown to appear early and has demonstrated moderate stability for children who show behavioral inhibition across settings or tasks (e.g., Kagan, Snidman, Kahn, \& Towsley, 2007). 
Kagan and colleagues $(1987 ; 1988 ; 2001)$ have demonstrated that behavioral inhibition has both genetic and environmental influences. High physiological reactivity related to behavioral inhibition has been observed in children as young as 4 months old (Kagan \& Snidman, 1991; Schwartz, Kunwar, Greve et al., 2010). Crying in the presence of novel visual and auditory stimuli at 4-months-old has been shown to significantly predict behavioral inhibition (i.e., avoidance of novel stimuli) at 14-months-old (Moehler et al., 2008) and has been related to structural difference in the brain by age 18 compared to those who were uninhibited infants (Schwartz et al., 2010). By 21 months old, 20-28\% of toddlers demonstrate high levels of reticence and withdrawal (i.e., behaviorally inhibited), $32-40 \%$ of infants were not wary in any setting (i.e., uninhibited), and approximately $40 \%$ showed intermediate levels of fearfulness (Kagan \& Snidman, 1991; Kagan, Reznick, \& Snidman, 1987). Schwartz, Reznick, and Kagan (1999) followed the same cohort from 21 months old to 13 years old and found that $22 \%$ of behaviorally inhibited boys and $44 \%$ of behaviorally inhibited girls met criteria for social anxiety disorder by age 13. These problems seem to appear even sooner than adolescence, however. Children who show signs of behavioral inhibition (based on motor activity and crying as in Kagan \& Snidman, 1991) in infancy show low levels of social approach behavior by the start of kindergarten (Rimm-Kaufman \& Kagan, 2005), suggesting that early social differences may relate to the development of social anxiety disorder. Hirshfeld-Becker and colleagues (2007) assessed children at ages two- to six-years-old and again five years later and found that children who displayed high levels of behavioral inhibition at the first assessment had a 2.37 fold greater chance of having social anxiety disorder at the second assessment than nonbehaviorally inhibited children.

It should be noted that while many studies have demonstrated stability of behavioral inhibition from infancy to toddlerhood and early childhood using observational measures, many of these same studies and others have noted inconsistencies in behavioral inhibition across development. Kagan, Snidman, and Arcus (1998) observed a relation between extreme high 
reactivity at 14 months and behavioral inhibition at 4.5 years (10 out of 74 initially high reactive children). They also found that a similar portion of children (15 out of 74 children) had previously shown high reactivity and fearfulness as infants, but at age 4.5 no longer showed inhibited behavior with adults or peers. Pfeifer, Goldsmith, Davidson, and Rickman (2002) also demonstrated developmental discontinuity of behavioral inhibition from toddlerhood to elementary school. They found that $74 \%$ of formerly inhibited 32 -month-old toddlers were no longer classified as high in inhibition by 7 years of age. Additionally, Rubin, Hastings, Stewart, Henderson, and Chen (1997) found that only $46 \%$ of toddlers who were behaviorally inhibited upon exposure to novel adults, novel toys, and laboratory situations were also inhibited toward novel peers. This finding suggests that a more specific indicator may be necessary to relate to the peer environment specifically. High levels of inhibition may be relatively stable, but less extreme levels of inhibition may not be as stable from infancy to childhood. For this reason, some researchers have sought to identify more proximal risk factors during the preschool period when children may begin experiencing social impairment. Studies identifying these factors will now be reviewed.

\section{Social indicators of behavioral inhibition in infancy and toddlerhood. When} assessing behavioral inhibition, different researchers have identified specific social behaviors which correlate with high reactivity, reticent behavior, and anxiety in infancy and beyond. Observations of behavioral responses during various novelty lab tasks have been used consistently to measure behavioral inhibition. Kagan and colleagues (Garcia-Coll et al., 1984; Kagan, Reznick, \& Snidman, 1987; Kagan \& Snidman, 1991; Kagan, Snidman, \& Arcus, 1998) classified infants as highly reactive or behaviorally inhibited when they exhibited high motor activity (e.g., movement of arms and legs and arching of the back) and crying during a battery of stimulating tasks. Depending on the specific age of assessment, tasks included separation from the parent, listening to unfamiliar voices, presentation of novel toys (e.g., colorful mobile, noisy 
plastic toys, rotating toys, and toys that moved on their own), and presentation of unpleasant smells and tastes.

Buss, Davidson, Kalin, and Goldsmith (2004) examined the freezing response and stress reactivity across different levels of threat in a sample of 24-month-old toddlers under different levels of restraint (i.e., high chair vs. free play). Freezing is considered the third fear response (i.e., fight, flight, and freeze); however in the absence of directly dangerous stimuli, freezing may indicate maladaptive behavior. These authors found that highly reactive toddlers displayed significantly greater amounts of freezing in the least restricted approach task, suggesting that this particular fear response may be less adaptive and more dysregulating in the more inhibited toddlers.

Kagan and Snidman (1999) used the number of spontaneous comments and the number of smiles to categorize children as inhibited, but then created a composite rating of overall inhibition to relate to their outcome variables rather than exploring the individual utility of each behavioral component. These researchers have continued to examine spontaneous comments and smiles longitudinally to find that that children rated as highly reactive at 4 months to 2 years continued to exhibit fewer smiles and fewer spontaneous comments at age 7 (Kagan, Snidman, Zentner, \& Peterson, 1999) and at age 13 (Schwartz, Snidman, \& Kagan, 1999). Schwartz, Reznick, and Kagan (1999) found that those who were inhibited at 21 months displayed significantly different social skills (i.e., smiling less and making fewer spontaneous comments) by age 13. Smiles and spontaneous comments at age 7 did not, differentiate children who had been behaviorally inhibited in infancy and went on to suffer from anxiety from those who did not go on to suffer from anxiety. Smiles, but not spontaneous comments, predicted generalized social anxiety disorders in historically highly reactive 13-year-olds (Schwartz et al., 1999).

Kennedy, Rapee, and Edwards (2009) observed children's behavior during interactions with a female assessor playing with novel toys, interactions with a masked stranger, 
engagement with physically challenging equipment, and singing a song into a microphone. They coded latency to the child's second spontaneous speech, total duration of child's speech, time spent within one arms' length of the mother, the frequency of the child's stares at the assessor, the number of approaches (verbal and physical) to the costumed stranger, whether the child played with the "novel" toy, and the number of refusals on any task. Unfortunately the authors did not examine specific behaviors displayed during these tasks, but formed a composite score of behavioral inhibition.

Social indicators of preschool risk for anxiety. Adult retrospective reports have revealed that inhibition toward social stimuli (i.e., shyness, as opposed to inhibition toward objects) during the preschool period may be particularly relevant to the development of anxiety and depression (Neal, Edelmann, \& Glachan, 2002) and may be distinct from inhibition toward inanimate objects (Dyson, Klein, Olino, Dougherty, \& Durbin, 2011). For many children, preschool is an initial opportunity to interact with many different peers. New social challenges provide opportunities to develop emotional and social skills. In the preschool years (typically ages 3-5), children typically engage in parallel play and increasing frequency of cooperative play (Piaget, 1965; Rubin, Bukowski, \& Parker, 2007). Social learning theorists have demonstrated that successful peer interactions consist of an interchange of social reinforcement (Charlesworth \& Hartup, 1967). Social contact, talking, cooperation, and positive affect have been shown to increase future successful social interactions across the preschool years and typically develop rapidly from age 3 to 4 (Charlesworth \& Hartup, 1967; Denham et al., 2001; Newcomb \& Bagwell, 1996; Waters \& Sroufe, 1983). "In general, the young child who successfully negotiates the developmental task of sustained positive engagement with peers is in a good position to continue thriving in a social world" (Denham, 2006a, p. 60). While most children increase in their social play throughout preschool and elementary school (Rubin, Bukowski, \& Parker, 2007), shy children have been observed to withdraw socially, meeting new social challenges with reticence and attempts to avoid social interactions with peers and adults 
(Asendorpf, 1991; Engfer, 1993; Rubin \& Asendorpf, 1993). These children may not acquire the same social skills as their less shy peers and may begin to diverge from the typical social developmental course (Schwartz, Reznick, \& Kagan, 2010; Spence, Donovan, \& BrechmanToussaint, 1999; Younger, Gentile, \& Burgess, 1993). Asendorpf, Denissen, and van Aken (2008) found that children who were rated as high in behavioral inhibition during a lab task at age 3 later reported a significant delay in first romantic partnership (+8 months) and a delay in first time employment (+10 months) during emerging adulthood compared to their historically less inhibited peers. What begins as relatively small differences in social behavior, over time develops into larger differences that could mean general quality of life and economic disparities.

Observational studies have been instrumental in understanding typical and abnormal social development as they relate to anxiety. As with infant behavioral inhibition, interactions with novel adults in laboratory simulations appear to be good indicators of shyness and social behavior with peers (e.g., Asendorpf, 1992). Rotenberg and colleagues (2003) manipulated adults' responses to children's behavior while coding "nervous non-verbal behaviors" (i.e. gratuitous hand, leg, and foot movements), smiling, and verbal utterances. Mothers rated their child's shyness as the extent to which the child "warms up easily to new people," "likes to talk about himself/ herself to new people," and "is sociable with people he/she doesn't know well." Rotenberg and colleagues found that shy children spoke fewer utterances and smiled less than their peers, regardless of adult behavior, but did not assess peer interactions (i.e., did not demonstrate relatedness of the measure). Volbrecht and Goldsmith (2010) observed children's behavior while approached by a novel adult, children's approach toward novel toys, and delay of gratification to assess behavior inhibition and control in a 4 year longitudinal study of twins ages 3 to 7. During the novel adult approach task, Volbrecht and Goldsmith observed vocal distress, activity level, approach and avoidance, eye gaze, verbal hesitancy, and nervous fidgeting. Although they reported that these variables accounted for more than half of the variance in approach behavior, they analyzed only two composite variables, labeled "active/expressive fear" 
and "inhibited/withdrawn fear." These authors compared the composite variables to parentreport of child shyness, but did not compare their observational measure to peer interactions and anxious social withdrawal. While the lumping of variables to form composites is frequently done in order to capture the most variance in the model and to collapse across infrequent behaviors, this tactic does not illuminate the specific observable behaviors associated with impairment.

Restraint of speech with both unfamiliar adults and children also appears to be a sensitive index of behavioral inhibition and risk for anxiety (Asendorpf, 1992). Rezendes, Snidman, Kagan, and Gibbons (1993) found a significant relation between number of spontaneous comments made during a lab task and the number of comments made to peers during unstructured play from 2 years old to 6 years old. Keller and Carlson (1974) found that preschool-aged children who avoided peer interactions (i.e., social withdrawal) dispensed significantly lower rates of social reinforcement (3.72 in 6 minutes), such as verbalization, imitation, smiling, sharing, and affection when interacting, compared to their non-withdrawn peers (13.02 behaviors in 6 minutes). Although these studies have used observational measures to identify differences in social interactions for shy children, it remains unclear how each social behavior in preschool may aid in identification of anxious social withdrawal and may relate to social anxiety development.

Avoidance of peer interactions (i.e., anxious social withdrawal) may be an important link between shyness and social anxiety disorder (Gazelle, 2010). For many children, wariness in social situations does not impact their functioning, but for a subset of children, shyness leads to impairment in social interactions and increased risk of anxiety (Gazelle, 2010). Although there are different functions of social withdrawal, the studies referenced herein and the current study are concerned with anxious social withdrawal during which children seek to avoid social interactions in order to avoid anxiety (see Asendorpf, 1990; Asendorpf \& Rubin, 1993; Gazelle \& Rubin, 2010). Anxious social withdrawal is most commonly observed as "watching peers' play 
without joining" (p. 69, Gazelle, 2010). These children often withdraw socially, not due to social disinterest, but out of fear (Coplan, Prakash, O'Neil, \& Armer, 2004; Coplan, Rubin, Fox, Calkins, \& Stewart, 1994).

Many studies of shyness have focused on social withdrawal in the presence of unfamiliar peers and adults. While problematic anxious social withdrawal frequently is stable across interactions with both unfamiliar and familiar peers (Engfer, 1993; Rubin \& Asendorpf, 1993; Younger, Gentile, \& Burgess, 1993), social withdrawal from familiar peers may play an important role toward interpersonal stress possibly related to social anxiety development (Rubin \& Asendorpf, 1993). Children who display anxious solitary behavior (with familiar or unfamiliar peers) in kindergarten likely will continue to experience increasing withdrawal from familiar peers throughout elementary school (Asendorpf \& van Aken, 1994; Gazelle \& Ladd, 2003).

\section{Study Aims}

Observation within the peer environment remains the gold-standard method for assessing shyness and social withdrawal in young children; however it is not always feasible for community clinicians, who often provide interventions, to conduct formal observations within a peer environment. Despite the need for early intervention, children currently are infrequently identified, perhaps due to barriers to implementing elaborate assessment tools in school settings with young children (Conroy \& Brown, 2004). Currently, there are not transportable methods for identifying the preschoolers who may be at highest risk for peer problems and social anxiety. Although shyness is a trait that may be identifiable when meeting a new person, there currently are no empirically derived guidelines for deciphering which observed behaviors relate to impairment in preschoolers and which may not.

The current study sought to establish an observational method and coding system to identify specific child behaviors during a brief task with a novel adult that relate to social anxiety across setting (i.e., shyness with the novel adult and solitary behavior during unstructured play), across informant (i.e., observer rating and parent-report), and across time (i.e., preschool to 
elementary school). The coding system was based on the above reviewed studies that have identified anxious behaviors exhibited by young children in social situations (Buss, Davidson, Kalin, \& Goldsmith, 2004; Kagan \& Snidman, 1999; Keller \& Carlson, 1974; Kennedy, Rapee, \& Edwards, 2009; Volbrecht \& Goldsmith, 2010), but aimed to extend these studies by illuminating the individual behaviors which may serve as "risk" markers of anxiety in early childhood. Additionally, the study sought to identify the specific behaviors that may be most reliable indicators across parent-report and observed social withdrawal. This may be a particularly important question to aid in understanding the different behaviors which parents and peers respond to when making observations of the child, shaping child's environment, and maintaining social anxiety. Third, this study examined whether the behaviors identified by the preschool coding system predict social anxiety and social impairment several years later when children are in elementary school.

\section{Research Questions (RQ) and Hypotheses (H)}

RQ1. Which global observations made during an interaction task with a novel adult explained a significant portion of variance in solitary behavior during unstructured play?

H1a: It was hypothesized that a significant portion of variance in solitary behavior during unstructured play would be explained by the combined prediction of the global ratings of shyness, postural rigidity, and volume of speech during the interaction task. Although these codes are not independent, it was thought that the gestalt of shyness encompassed behavior that would be related to social impairment over and above postural rigidity or volume of speech.

$\mathrm{H} 1 \mathrm{~b}$ : Examining the individual contribution of each predictor, it was hypothesized that the global rating of shyness would explain the most variance in solitary behavior during unstructured play, given that it was the most encompassing impression of behavior. Based on the significant loading of verbal hesitancy in Volbrecht and Goldsmith (2010) and the contribution of whispering in Glennon and Weisz (1978), it was hypothesized that volume of speech second would explain the next largest portion of variance in solitary behavior during unstructured play. Postural rigidity 
was hypothesized to explain the least variance in solitary behavior during unstructured play, based the lack of significant relations of rigidity with parent-report or teacher-report in Glennon and Weisz (1978).

RQ2. Which specific behaviors displayed during the interaction task were related to solitary behavior during unstructured play and to parent-report of child anxiety?

H2a: Based on previous findings on the social skills of anxious and inhibited children (e.g., Asendorpf, 1992; Keller \& Carlson, 1974; Rezendes et al., 1993), it was hypothesized that solitary behavior during unstructured play and parent-report of child anxiety would be positively related to eye gaze aversion, non-verbal response to a direct question, physical distancing, and freezing and to the proportion of verbal behaviors that were direct responses during the interaction task with a novel adult. It was hypothesized that solitary behavior during unstructured play and parent-report of child anxiety would be negatively related to smiling and to the proportion of verbal behaviors that are commands, questions, and unsolicited conversation during the interaction task with a novel adult.

Exploratory RQ3: Which specific behaviors displayed during the interaction task were differentially related to parent-report of child anxiety and solitary behavior during unstructured play? To aid examiners in incorporating multi-method, multi-informant assessment, this research question sought to identify those behaviors which correlated significantly across method and informant and those behaviors which were divergent across method and informant.

RQ4: Which specific behaviors displayed during the interaction task in preschool related to impairment in school-aged children at longitudinal follow-up?

H4a. It was hypothesized that parents' report their school-aged child's social anxiety would be positively related to preschool eye gaze aversion, non-verbal response to a direct question, physical distancing, and freezing and to the proportion of verbal behaviors that were direct responses during the interaction task with a novel adult. 
H4b. It was hypothesized that school-aged children's self-report of social anxiety would be positively related to preschool eye gaze aversion, non-verbal response to a direct question, physical distancing, and freezing and to the proportion of verbal behaviors that were direct responses during the interaction task with a novel adult.

H4c. It was hypothesized that parent-reported social functioning in school-aged children would be negatively related to preschool eye gaze aversion, non-verbal response to a direct question, physical distancing, and freezing and to the proportion of verbal behaviors that were direct responses during the interaction task with a novel adult.

\section{Method}

\section{Participants}

Participants were children who participated in the Assessment of Shyness in Early Childhood study conducted between August of 2007 and February of 2008. The preschool portion of this study was conducted in conjunction with one study aimed to develop a self-report measure of social anxiety (Chorney, 2009) and another study by this author examining the association of facial affect labeling and social anxiety (Ale, Chorney, Brice \& Morris, 2010). The behaviors displayed during the interaction phase of the stranger-child task (described below) have not previously been coded and are unique to the current project.

Participating children were between the ages of four and five. Children were recruited from three Morgantown area preschools. A total of 99 parents of four- and five-year-old children were solicited and 30 parents $(30.3 \%)$ consented to participate. One child moved away prior to completion of the observational task and two children's observational tasks were not video recorded due to equipment malfunctioning, thus a total of 27 children were included for analyses. The majority of parent respondents were mothers (96.3\%) and were highly educated; over $80 \%$ held a college degree (with over $40 \%$ holding a post-baccalaureate degree). The sample was predominantly Caucasian, non-Hispanic (96.3\%) and included one Hispanic child. Verbal assent was attained from all participating children prior to engaging in study procedures. 
Upon completion of the preschool portion of the study, a monetary donation was made to the preschool to supply new equipment and classroom resources.

During the original study, the consenting parent was asked to provide his or her name, address, phone number, and email address. All of the original 27 preschool participants, were re-contacted by email $(n=23)$, phone $(n=11)$, or mail $(n=2)$ and asked to participate in the longitudinal follow-up between October and November of 2011. A total of 16 parents and 15 children (55\%) consented to participate in the follow-up portion of the study by completing questionnaires through a secure website. While all parents and children consented to participate on the website and completed the majority of questionnaires online, 10 children were then contacted by phone to complete one or more missing items.

Participating children were $50 \%$ female and between the ages of 8 and 9 at the follow-up assessment. Upon completion of the follow-up portion of the study, participating families were mailed a $\$ 10$ gift certificate. Those who participated in the follow-up did not differ significantly from those who did not on child gender, $X^{2}(1, N=27)=0.05$, n.s.; child's age at initial assessment, $t(26)=0.01$, n.s; parent-reported anxiety $t(26)=0.24$, n.s.; or percentage of solitary behavior during unstructured play, $t(26)=3.27, p<.08$. Although not all parents initially provided educational information, based on existing data, parents who participated in the followup were significantly held significantly higher degrees than those who did not, $X^{2}(3, N=24)=$ $9.20, p<.05$.

\section{Measures}

In order to develop an observational measure of specific risk behaviors, preschool-aged children were engaged in the stranger-child task. To examine the relatedness and consistency (Cichetti \& Wagner, 1990) of these specific behaviors, their behaviors during the stranger-child task were compared to solitary behavior during unstructured play, to parent-report of child anxiety and parent- and self-report of their social behavior and anxiety during elementary school. 


\section{Behavioral Observations.}

Stranger-child task. Children were engaged in the Stranger-child task (Bishop, Spence, \& McDonald, 2003), which was adapted from Asendorpf (1987). Similar stranger tasks have been used consistently in the behavioral inhibition and early childhood literatures (e.g., Kagan, Reznick, Clark, Snidman, \& Garcia-Coll, 1984; Kennedy, Rapee \& Edwards, 2009). This task consists of three stages, Pre-Observation, Pre-Interaction phase, and Interaction phase (as described below), during which the child's behavior is coded. For the purposes of the current investigation children's behaviors were coded during the Interaction phase.

The Pre-Observation phase began with the child being led to the observation room by a familiar female researcher. The researcher led the child to a specified mark on the rug and said to the child, "There are some blocks in here. You can play with them if you like." The researcher left the child saying, "I'll be back in a little while. You stay here and play with these blocks." A stranger then entered the observation room. The stranger was a Caucasian young-adult male confederate dressed in casual clothes.

Upon the stranger's entry into the observation room, the Pre-Interaction phase began. The stranger walked directly into the room and sat on the rug approximately 2 meters from the child. The Pre-Interaction phase ended when the child first spoke or after 3 minutes if the child did not speak.

Upon commencement of the Pre-Interaction phase, the Interaction phase began. During the Interaction phase, the stranger's body faced the child and he directed his attention toward the child. If the child initiated conversation during the Pre-Interaction phase or at the beginning of the Interaction phase, the stranger responded appropriately, but did not make further attempts at conversation. If the child had not initiated conversation with the stranger, the stranger asked the child a scripted question at the start of the Interaction phase. In either instance of the child's behavior, the stranger made further prompts following 15 seconds of continuous silence. The stranger first asked the child if he or she had any pets and then 
followed with scripted questions about siblings and vacations. After 3 minutes in the Interaction phase, the stranger thanked the child for talking to him and the familiar female researcher reentered the room to take the child back to the classroom activity.

The Pre-Interaction and Interaction phases were video recorded with one camera which was directed at the child. The recordings of the Interaction phase were viewed and raters made global ratings of the child's behavior, as well as coding occurrences of non-verbal and verbal behaviors.

Global codes. Coders made global ratings of behavior after viewing the 180 second task Interaction phase (as in Asendorpf, 1992). Shyness, postural rigidity, and volume of speech were rated on a zero to four Likert-type scale. For the shyness rating, zero represented outgoing children (e.g., initiates contact, appears confident, frequent speech, requires no prompting) and four represented children who display very shy behavior (i.e., not talking, gazing at stranger, fearful facial expression and/or crying). For volume of speech, zero reflected predominantly inaudible speech and four reflected clear speech, at times yelling. For postural rigidity, zero reflected limp posture and four reflected very rigid and stilted movements. Interobserver agreement was established on $25 \%$ of observations using interclass correlation coefficient and achieved adequate reliability for the three global codes (shyness $=.95$; volume of speech $=$ $1.00 ;$ postural rigidity $=.75)$.

Microanalytic codes. (Appendix A) Five non-verbal behaviors, specifically eye-gaze aversion, non-verbal responses to a direct question, physical distancing from the stranger, freezing, and smiling were coded. Interobserver agreement (IOA) was established on $25 \%$ of data using effective percent agreement (i.e., [total agreed upon intervals / total responding intervals] x 100; Repp et al., 1976) between the two raters. Eye gaze aversion was coded when the child's head and eyes were directed away from the stranger for the predominant portion of the interval $(\mathrm{IOA}=76.78 \%)$. Non-verbal response to a direct question was coded when the child displayed a shrug, head shake, nod, hand gesture or other non-verbal response within 3 
seconds of a direct question $(\mathrm{IOA}=71.42 \%)$. Physical distancing was coded when the child was observed moving his or her body away from the stranger (IOA, not observed). This code reflected full body movement or noticeable leaning away from the stranger. Freezing was defined as the child being motionless for a minimum of 2 seconds (IOA, not observed). As previously defined by Rotenberg and colleagues (2003), smiling was defined as the child's mouth being curved in an upward $U$-shape for a minimum of 2 seconds $(I O A=82.14 \%)$.

Number of utterances spoken (total utterances), defined as complete thought or phrase, was recorded. Each verbal utterances was coded as direct response (IOA = 85.10\%), command $(\mathrm{IOA}=100 \%)$, question $(\mathrm{IOA}=76.47 \%)$, or other unsolicited conversation $(\mathrm{IOA}=79.41 \%)$.

Unstructured Play Behavior. Children were observed during a period of unstructured play on the playground or indoors for 15 consecutive minutes. During the observation period, trained raters used a continuous interval recording procedure to code peer interaction behavior at ten seconds intervals. The observers identified positive peer interaction, negative peer interaction, and solitary play (as in Morris, Messer, \& Gross, 1995, following Strain \& Timm, 1974). For the current study, only solitary play behavior was examined, as a proxy for social withdrawal. Solitary play was coded when the target child did not engage with peers. This type of behavior also consisted of on-looking and wandering. As the purpose of these observations was to capture child-peer interactions, teacher-directed interactions were not coded. If the child engaged the teacher or the teacher intervened, coding was stopped and resumed when the child was no longer interacting with the teacher. This coding system has demonstrated excellent interobserver agreement in a sample of kindergarten children (96.31\%; Morris, Messer, \& Gross, 1995). Interobserver agreement for the current raters was verified on $20 \%$ of the observations and achieved $99 \%$ agreement.

\section{Parent-report.}


Guardians completed a demographics questionnaire, providing socioeconomic and ethnicity information for the parent, his or her spouse (if applicable), and the child (see Appendix C).

Spence Preschool Anxiety Scale. Parents completed the 27-item Spence Preschool Anxiety Scale (SPAS; Spence, Rapee, McDonald, \& Ingram, 2001). The SPAS was adapted for developmental sensitivity from the Spence Anxiety Scale (Spence, 1998). Spence and colleagues (2001) suggest that a score of one standard deviation above the mean indicates possible clinical levels of anxiety and a half of one standard deviation indicates elevated anxiety.

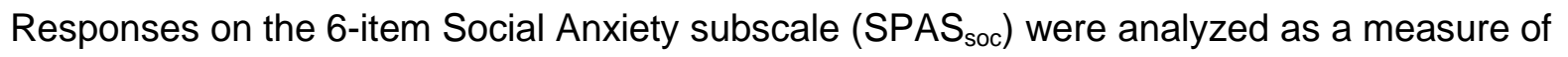
parent-reported "social anxiety." Although reliability and validity data for the SPAS have not

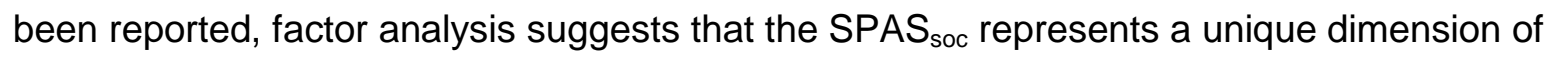
anxiety, explains $40-60 \%$ of the variance in preschool children, and contributes to one higher order factor of anxiety in general (Spence et al., 2001). In the current sample, the SPAS soc $_{\text {items }}$ had adequate internal consistency (alpha $=.67$ ).

Social Phobia and Anxiety Inventory for Children-Parent Version (P-SPAIC). Recontacted parents completed the 26-item P-SPAIC (Beidel, Turner, Hamlin, \& Morris, 2000) with regard to their child's behavior at the follow-up assessment. Parents rated each item on a 3point Likert-type scale $(0=$ never or hardly ever, $1=$ sometimes, and $2=$ most of the time or always). The total score was used for data analysis. In previous studies, the P-SPAIC has shown moderate convergence with the child report SPAI-C $(r=.31-.43)$ and parent report of negative affectivity, as well as significant discriminability from externalizing behaviors (Beidel, Turner, Hamlin, \& Morris, 2000; Higa, Fernandez, Nakamura, Chorpita, \& Dalieden, 2006).

Child Behavior Checklist (Achenbach, 1991). Parents completed the social competence subscale of the Child Behavior Checklist (CBCL) as a measure of social functioning. The CBCL contains three competence scales (activities, social, and academic) to assess adaptive functioning, in addition to behavior problem scales. The social competence 
subscale is comprised of 6 items assessing the child frequency and quality of social interactions. These items have demonstrated good test-retest reliability with mothers of 7 - to 9year-old children over a 12 month $(r=.76)$ and 24 month $(r=.43)$ period (Achenbach \& Rescorla, 2001). Additionally, children referred for evaluation of a mental health problem scored significantly lower on the social competence subscale than non-referred community children, indicating good discriminant validity (Achenbach \& Rescorla, 2001).

\section{Self-Report}

During the follow-up assessment, the 8- to 9-year-old participants were asked to complete a self-report about their behavior.

Social Phobia and Anxiety Inventory for Children-Short Form (SPAIC-10). The SPAIC-10 is a 10 -item measure of social anxiety symptoms empirically derived from the 26 -item SPAI-C (Beidel, Turner, \& Morris, 1995). Total scores over 7 indicate possible social anxiety disorder. The total score of the SPAIC-10 was used to assess child self-report of social anxiety. Although analyses for the SPAIC-10 have not been published, these 10 items demonstrated the best discriminability and overall association with the total score of the 26 -item version in the original measure development studies (T. Morris, personal communication, June 9, 2011). The original 26-item SPAI-C has well established discriminant validity within anxiety disorders, convergent validity with observational ratings of social anxiety, and excellent overall internal consistency (alpha = .92) in samples of children as young as 8-years-old (Beidel, Turner, \& Fink, 1996; Beidel, Turner, Hamlin, \& Morris, 2000). As with the P-SPAIC, children rated each item on a 3point Likert-type scale $(0=$ never or hardly ever, $1=$ sometimes, and $2=$ most of the time or always). Seven of the items have sub-items assessing the degree of distress by audience type (i.e., familiar peers, unfamiliar peers, or adults) which are averaged when creating a total score.

\section{Procedure}

The above measures were used to establish the stranger-child task coding measure. This videotaped task was coded and compared to parent-report and observations with peers 
during the preschool period, as described below. Children participated in the stranger-child task and were observed in unstructured play after October of the school year and within a three month time frame. Families were re-contacted and completed questionnaires online when the child was in elementary school in order to establish the predictive validity of the stranger-child task coding measure. The same parent who completed the preschool questionnaires was not required to complete questionnaires at follow-up, although this may have occurred.

Stranger-child Task. The stranger-child task was coded for global ratings and for frequency of specific behaviors (i.e., microanalytic codes) by two graduate-level raters. Coders watched the recorded task twice for each participant. Both of the viewings were made sequentially and within one sitting to standardize exposure to each child's behaviors. All observations were recorded on the stranger-child task Coding Forms (Appendix B) and instances of each behavior were totaled.

Global codes. On the first viewing, the coders did not record while watching the video. At the end of the 180 second task period, coders recorded ratings for each global code.

Microanalytic codes. On the second viewing, an interval recording procedure was used to record verbal and non-verbal behaviors. The "observe-and-record" method used allows coders to record all intervals in which behavior occurs, rather than sampling behavior from the observation period and risking missing low base-rate behaviors (Repp, Roberts, Slack, Repp, \& Berkler, 1976). Jackson, Della-Piana, and Sloane (1975) suggest recording at an interval size that is small enough to capture the "usually separate occurrences of the behavior but large enough to allow you to observe and record reliably and consistently for the entire time you will be observing." (p. 33). For the current project, data was recorded at ten second intervals for the duration of the Interaction Phase of the stranger-child task.

Non-verbal behaviors were given a score of 1 for each interval in which they occurred. The number of intervals in which each non-verbal behavior occurred was then be totaled to create one score for each non-verbal behavior. 
Each interval during which the child produced an audible utterance was coded for content as a direct response, a command, a question, or other unsolicited conversation. Total utterances were calculated by summing the number of intervals during which any type of utterance occurred. Percentage of each type of utterance out of total utterances was calculated to produce a score for each verbal code.

Follow-up. Parents of children who participated in the preschool phase of the study were recontacted by email, telephone, and mail. If the provided email was no longer functional, they were contacted by phone. If they could not be contacted by telephone, they were sent a letter in the mail and asked to respond to the online questionnaires. If their contact information was not provided or was no longer accurate, publicly available information on the internet was searched in an attempt to obtain current contact information. Upon contact, a parent and his or her child was asked to provide consent electronically using an electronic survey system. The parent and child then completed the questionnaires electronically or by telephone.

Due to the lack of a gold-standard assessment tool in elementary school, multiinformant, multi-method assessment was used to classify children as having problematic anxiety at the follow-up assessment. If children or parents reported significantly elevated anxiety (i.e., on any of the three follow-up measures), children were classified as having problematic social anxiety at the school-aged follow-up assessment. Elevations were determined to be one standard deviation above published normative means. When published data were not available (i.e., SPAIC-10), one standard deviation about the sample mean was determined to be "problematic." Six children met criteria for problematic social anxiety (i.e., the elevated group) and nine children did not meet criteria (i.e., the not elevated group) at the follow-up assessment.

\section{Results}

Preliminary analyses. Descriptive statistics for all observational, parent-report, and child-report variables from preschool and follow-up are presented in Table 1. While the global codes and most of the micro-codes were within parameters of normality, non-verbal response 
$(\max =6)$, physical distancing $(\max =2)$, freezing $(\max =10)$, and smiling $(\max =7)$ were observed at low frequency and thus were significantly skewed and kurtotic. Commands and questions were also significantly kurtotic. Solitary play behavior, all parent-report measures (SPAS, SPAIC, and CBCL) and child self-report measures (SPAIC-10) were normally distributed.

Post-hoc power analyses were conducted using $G^{*}$ Power 3.1 (Faul, Erdfelder, Buchner \& Lang, 2009) and will be presented for each analysis below.

Intercorrelations for all global and micro-codes are presented in Table 2. Due to the nonnormal distribution of several of the coded behaviors, Spearman's correlation coefficients were used to compare means. The global behaviors were significantly correlated among one another $\left(r_{s}=.62-.76, p<.01\right)$ and with all micro-codes $\left(r_{s}=-.29-.93, p=.01-.05\right)$, except commands with postural rigidity $\left(r_{s}=.23\right.$, n.s. $)$, physical distancing with all global codes $\left(r_{s}=-.03-.01\right.$, n.s. $)$, and freezing with volume of speech and postural rigidity $\left(r_{s}=-.34\right.$ and -.37 , n.s.). Examining the intercorrelations among the micro-codes, questions was significantly correlated with commands $\left(r_{s}=.46, \mathrm{p}<.05\right)$, unsolicited conversation $\left(r_{s}=.62, \mathrm{p}<.05\right)$, direct response $\left(r_{s}=-.78, \mathrm{p}<.01\right)$, gaze aversion $\left(r_{s}=-.51, \mathrm{p}<.01\right)$, non-verbal response $\left(r_{s}=-.59, \mathrm{p}<.01\right)$, freezing $\left(r_{s}=-.51, \mathrm{p}<\right.$ $.01)$, and smiling $\left(r_{s}=.39, \mathrm{p}<.05\right)$. Unsolicited conversation was significantly correlated with direct response $\left(r_{s}=-.93, \mathrm{p}<.01\right)$, gaze aversion $\left(r_{s}=-.54, \mathrm{p}<.01\right)$, non-verbal response $\left(r_{s}=-\right.$ $.70, \mathrm{p}<.01)$, and freezing $\left(r_{s}=-.38, \mathrm{p}<.01\right)$. Direct Response was significantly correlated with gaze aversion $\left(r_{s}=.55, \mathrm{p}<.01\right)$, non-verbal responses $\left(r_{s}=.74, \mathrm{p}<.01\right)$, freezing $\left(r_{s}=.42, \mathrm{p}<\right.$ $.05)$, and smiling $\left(r_{s}=-.39, \mathrm{p}<.05\right)$. Additionally, gaze aversion was significantly correlated with non-verbal response $\left(r_{s}=.40, \mathrm{p}<.05\right)$ and smiling $\left(r_{s}=-.58, \mathrm{p}<.01\right)$. Non-verbal response was significantly correlated with freezing $\left(r_{s}=.41, \mathrm{p}<.05\right)$. Physical distancing was not correlated with any other global or micro-coded behavior. Post-hoc power analysis revealed that a sample of this size has an $80 \%$ chance or greater (Cohen, 1988) of detecting a correlation of \pm .37 or greater. 
RQ1. Which global behaviors observed during an interaction task with a novel adult explained a significant portion variance in solitary behavior during unstructured play? A linear multiple regression analysis was conducted with global codes (postural rigidity, volume of speech, and shyness; IVs) predicting solitary behavior during unstructured play (\% observed in solitary play, DV). The combined prediction of the shyness, volume of speech, and postural rigidity explained $26 \%$ of the variance in solitary behavior during unstructured play, $R^{2}=.26, F$ $(3,23)=2.73, p=.07 ;$ (see Table 3). The post-hoc power analysis revealed that in order for an effect of this size to be detected ( $80 \%$ chance; Cohen, 1988) as significant at the .05 level, a sample of 47 participants would have been required $(1-\beta=.46)$.

To determine each predictor's contribution to the total variance accounted for by the model, the squared product-moment correlation $\left(r^{2}\right)$ for each global observation predictor (shyness, then postural rigidity, and then volume of speech) was examined in relation to solitary behavior during unstructured play. Postural rigidity was the strongest predictor $\left(r^{2}=.24, \beta=.30\right.$, n.s. $)$, then volume of speech $\left(r^{2}=.22, \beta=.21\right.$, n.s. $)$, then shyness $\left(r^{2}=.16, \beta=.04\right.$, n.s. $)$.

RQ2. Which specific behaviors displayed during the interaction task were related to solitary behavior during unstructured play and to parent-report of child anxiety? Spearman's correlations were conducted to analyze the magnitude of the relations of the five verbal microcodes (total utterances, percentage of utterances that are commands, questions, unsolicited conversation, direct responses) and five non-verbal micro-codes (eye gaze aversion, non-verbal response, physical distancing, freezing, smiling) with observed solitary freeplay behavior, as presented in Table 4. None of the micro-codes were significantly correlated with solitary freeplay behavior.

A second set of Spearman's correlations were conducted to assess the magnitude of the relations of the five verbal and five non-verbal micro-codes with the parent-reported Spence Preschool Anxiety Scale social anxiety score (SPAS ${ }_{\text {soc }}$ (see Table 4). None of the micro-codes were significantly correlated with the SPAS ${ }_{\text {soc. }}$. 
The current sample was powered to detect a significant Spearman's correlation of .50 or greater with $80 \%$ accuracy (Cohen, 1988). Thus, the above analyses were not adequately powered $(1-\beta=.05-.76)$ to detect a significant difference $(p<.05)$ in the current sample.

Exploratory RQ3. Which micro-coded behaviors displayed during the interaction task were differentially related to parent-report of child anxiety and observations of solitary behavior during unstructured play? Tests of dependent correlations were used to examine the magnitude of the relations of each micro-coded behavior with the parent-reported SPAS social anxiety score $\left(\mathrm{SPAS}_{\mathrm{soc}}\right)$ compared to the magnitude of the relation of each respective micro-coded behavior with solitary behavior. The Fisher's $r$-to-z transformation (see Meng, Rosenthal, \& Rubin, 1992) was used to compare the correlations over and above the correlation of solitary behavior and SPAS $\mathrm{soc}(r=.47, p<.01)$. None of the correlations were differentially related to observed solitary behavior and parent-reported SPAS ${ }_{\text {soc }}$, as displayed in Table 4. Post-hoc power analysis revealed that the comparison of smile-solitary behavior and smile-SPAS ${ }_{\mathrm{soc}}$ was adequately powered ( $1-\beta=.85)$, although no significant difference was present. Observed power for all other comparisons ranged from .17 to .65 , suggesting that the sample was not adequately powered to detect a significant relation (critical $z=-1.95$ ).

RQ4: Which specific behaviors displayed during the interaction task in preschool related to impairment in school-aged children at longitudinal follow-up?

Spearman's correlations were used to analyze the relations between each verbal and non-verbal coded behavior and elementary school assessments with the P-SPAIC total score, the CBCL social competency score, and the SPAIC-10 total score, as presented in Table 5. Physical distancing was not observed during the stranger-child task for any of the children who participated in the follow-up and therefore could not be compared to impairment at school-age. The parent-reported SPAIC total score was not significantly related to any of the preschool verbal or non-verbal micro-codes. The CBCL social competency score was significantly related to unsolicited conversation $\left(r_{s}=-.53, p<.05\right)$ and direct responses $\left(r_{s}=.57, p<.05\right)$. School- 
aged self-reported SPAIC-10 was not significantly correlated with any of the verbal or nonverbal micro-codes.

To further explore the relation between the preschool micro-coded behaviors and child social anxiety at follow-up (i.e., significant elevations on any of the three follow-up measures) one-way analysis of variance tests were conducted comparing each preschool micro-code (DV) for the follow-up groups (elevated group vs. not elevated group, IV). The one-way ANOVA revealed no significant micro-code by group interactions (see Table 6). There were however, large effects of follow-up group on total utterances $(d=.53)$, commands $(d=.47)$, and nonverbal response $(d=.68)$. There were moderate effects of follow-up groups on freezing $(d=.30)$ and unsolicited conversation $(d=.26)$ and small effects on questions $(d=.17)$, direct response $(d=.19)$, and gaze aversion $(d=.15)$. Post-hoc power analyses revealed that the current sample was not adequately powered to detect even the large effect as significant at the .05 level $(1-\beta=.08-.68 ;$ critical $F=4.67)$.

\section{Discussion}

The current study sought to develop an observational assessment procedure to readily identify specific behaviors which indicated social anxiety and social withdrawal in preschoolaged children. This study examined the relation of an observational assessment procedure to parent-reported child anxiety and to observed social withdrawal in preschool. To establish the predictive validity of this assessment method, the study also examined children's social anxiety and social adjustment 4-years later. Although there is a large literature identifying infant behavioral inhibition as a precursor to childhood social anxiety (e.g., Kagan et al., 1998; Hirshfeld-Becker et al., 2007; Pfeifer et al., 2002; Schwartz et al., 1999), this is the first study to using an analogue task with an unfamiliar adult to examine individual behaviors that relate to social anxiety and social impairment during the important preschool period of social development. Due to the small sample size and lack of adequate power at the preschool assessment and at the follow-up assessment, the hypotheses cannot conclusively be rejected 
nor accepted. Possible implications of the findings and limitations of the study will be discussed below.

\section{Findings}

The Observational Coding System. The study first sought to examine the inter-relations of the observed behaviors in the stranger-child task. Global and specific behaviors in the coding system for the stranger-child task were highly intercorrelated. The global codes (i.e., shyness, volume of speech, and postural rigidity) were moderately correlated, yet not multicollinear. This is particularly important because it suggests that each of the three global observations is distinct, but related. Since volume of speech and postural rigidity could be conceptualized as components of shyness, it is important to note that they were distinct from shyness and may offer unique assessment information about behavior exhibited by preschoolers during a social stressor. Additionally, the global and most of the micro-codes (i.e., questions, unsolicited conversation, direct responses, gaze aversion, and non-verbal responses) were correlated. The relation of global observations and specific behaviors suggest that the micro-coding method may be generalizable to broader observations. Teachers and parents likely refer children for an assessment of shyness and social anxiety based on these types of global observations, but behavior therapy requires intervention at a more specific behavioral level. Thus, it is important to establish the relation of individual behaviors to global observations.

In contrast, low base-rate behaviors (i.e., commands, physical distancing, and freezing) did not however establish concordance with global ratings or many of the other micro-codes. One interpretation of this low rate of occurrence could be that they are not relevant behaviors to social anxiety in preschool children. Given the theoretical relevance of physical escape behaviors and freezing behaviors (e.g., Buss et al., 2004; Kennedy et al., 2009) it may be more likely that the lack of association signifies that these behaviors are highly salient, occur only cases of extreme anxiety, and are infrequently displayed in specific contexts. Low base-rate behaviors have been a problem in previous observational attempts at assessing early childhood 
risk for anxiety (e.g., Edwards et al., 2010; Glennon \& Weisz, 1978; Kennedy et al., 2009; Volbrecht \& Goldsmith, 2010) and has necessitated the use of more global constructs in past studies. In addition to this assessment limitation, task type may contribute to the low rates of observation. Buss and colleagues (2004) found a significant difference in the frequency and duration of freezing depending on the task. Specifically, they observed less freezing during the stranger freeplay task than during the stranger restraint task or while being connected to physiological equipment by a stranger. It may be that the structure of the current study's stranger-child task did not allow for escape (i.e., physical distancing) or freezing, but rather children avoided and escaped the task by not speaking with the stranger or by avoiding eye contact. It is also possible that the task was not stressful enough to elicit physical distancing or freezing (perhaps more primal anxious responses) but was stressful enough to minimize verbal commands (likely an indicator of social assertion), even in those less inhibited children.

Across settings. A primary aim of the current study was to examine a transportable method of assessing risk for social anxiety that could be used outside of the peer environment, which is often difficult for clinicians to access. Given that solitary behavior during unstructured play and the stranger-child task both utilized direct observations of the child's behavior, it was hypothesized that the children's behavior would be consistent across social settings (i.e., with familiar peers and with novel adults). While there is evidence that children's inhibited behavior may vary considerably between social and non-social threatening stimuli, inhibition across social stimuli has demonstrated consistency (Asendorpf, 1992; Dyson et al., 2011; Rubin \& Asendorpf, 1993). Together, postural rigidity, volume of speech, and shyness explained $26 \%$ of variance in children's solitary behavior during unstructured play. Although this was not a significant amount of variance in the under powered regression analysis, the importance of these global observations should be further examined in future research. Particularly, postural rigidity was the strongest predictor. Children who displayed greater postural rigidity with the stranger adult may also display this type of stilted, rigid movement when on-looking toward peer 
interactions. This type of body posture was positively related to gaze aversion, non-verbal response, and freezing. Consistent with the behavioral theory of social skills development (e.g., Charlesworth \& Hartup, 1967; Keller \& Carlson, 1974), body stiffness, eye gaze avoidance, lack of verbalizations, and lack of movement is not likely to reinforce peer interactions. These global and specific behaviors that may be displayed during anxious social withdrawal may contribute to peer rejection. It is important to further explore postural rigidity as an observable behavior which may link early childhood anxiety, peer rejection, and the development of internalizing disorders (Gazelle \& Ladd, 2003; Gazelle \& Rudolph, 2004).

Given the consistency of behavioral inhibition across peer and adults contexts (Asendorpf, 1992), it is surprising that there were no significant associations between specific behaviors during the stranger-child task and children's solitary behavior during unstructured play. This may be due to the lack of power to detect significant effects in the current sample. One behavior observed in the stranger-child task which may warrant further consideration in future research was non-verbal response to direct questions (e.g., shrugging, nodding). Although not significant in the correlation analysis, non-verbal response was moderately correlated with solitary behavior during unstructured play. Children who avoided verbalizing in front of a stranger adult, even when asked a direct question may also avoid verbalizing in front of peers. Children who do not respond verbally when spoken to also may not be selected by peers for interactive games during unstructured play. Additionally, smiles and unsolicited conversation were negatively (although not significantly) related to solitary behavior during unstructured freeplay. The importance of not responding verbally, not smiling, and not making unsolicited conversation is consistent with past research which has demonstrated that socially withdrawn children display lower rates of social reinforcement (e.g., verbalizing, smiling, showing affection, and sharing) with peers than non-withdrawn children (Keller \& Carlson, 1974). Per cumulative continuity (Caspi, Elder, \& Bem, 1988; Roberts \& Caspi, 2003), initial solitary behavior and lack of socially reinforcing behaviors may lead to fewer peer interactions, 
peer rejection (Gazelle \& Ladd, 2003), and increased anxiety (Booth-LaForce, Oh, Kennedy et al., 2012; Coplan et al., 2004). These associations should be examined more closely in future research.

The lack of association of behaviors observed during the stranger-child task and solitary behavior in the peer context may be due in part to the different contexts in which children were observed. When with peers, children were observed naturalistically outside or in the classroom. When with the adult stranger, children were given the instruction to play with the blocks and were asked specific questions by the stranger. The prompts and instructions were given in order to provide the opportunity for a range of behaviors in a novel context. Unstructured play with peers may elicit different types of behaviors that were not relevant to a stationary task with an adult. The previous study utilizing this sample (Ale et al., 2010) found a bimodal distribution for latency to speak (i.e., some children spoke immediately and others did not speak at all) in a similar stranger-child task during which no prompting questions were provided. Future research should examine specific behavior children display when prompted by a peer. Additionally, although the study sought to extend previous literature which has examined solitary behavior with novel peers to assess behavior with familiar peers, solitary behavior in the context of familiar peers may be fundamentally different from solitary behavior with novel peers and behavior with novel adults (Rubin et al., 1997). Future work is needed to examine anxiety and specific social behaviors displayed with familiar versus unfamiliar peers and with familiar versus unfamiliar adults as it relates to social impairment.

Across Informants. Another aim of the current study was to examine the association of specific observed behaviors to parent-reported behaviors. There were no significant associations between specific behaviors observed during the stranger-child task and parentreport of children's social anxiety. This may also be due to the lack of power to detect significant effects in the current sample. Although not significantly related, parent-report of child social anxiety showed the strongest relation with non-verbal response to direct questions. Early 
childhood shyness and social anxiety are frequently identified by children's failure to respond verbally (American Psychiatric Association, 2000) and parents may experience this behavior as the most interfering for their child.

Although multi-informant report is frequently more discordant than mono-method or mono-informant report (Achenbach et al., 1987), the current findings indicate that the microcoded behaviors did not relate differentially to observed solitary behavior and parent-reported social anxiety. This is likely due to the low correlations of the micro-coded behaviors with either of the other report methods, as discussed above. The observations of peer solitary behavior and parent-report of child social anxiety displayed a significant relation with one another, however. This finding suggests that parents may be better reporters of young children's anxiety and social behavior than has previously been demonstrated (e.g., Glennon \& Weisz, 1978).

Predictive Validity. Preschool social anxiety and anxious social withdrawal has been related to increased social anxiety and peer rejection in elementary school (Asendorpf, 1990; Gazelle \& Ladd, 2003; Snidman, Kagan, \& Gibbons, 1993; Volbrecht \& Goldsmith, 2010). In the current study, parent-report of elementary school social competence was significantly negatively related to unsolicited conversation and was significantly positively related to direct responses. This is consistent with previous findings that spontaneous comments in early childhood are related to the development of social skills and positive peer interactions (Schwartz et al., 1999; Snidman et al., 1993; 1999). This may mean that preschool children who made unsolicited conversation were already displaying better social adjustment than those who only responded to the question posed to them. By the time children reached elementary school, these small differences in social behaviors manifest into larger differences in involvement in extra-curricular activities, frequency of peer interactions, and number of friendships.

When establishing any early identification method, it also is important to determine whether the observed behaviors relate to problematic levels of behavior in later childhood. Children who were rated as significantly more problematic on one of the three follow-up 
measures were compared to children who were not rated as problematic on any of the three follow-up measures. Due to the small cell sizes at follow-up and the number of comparisons made, the direct comparisons are less informative than examining effect sizes. There was a large effect of group on total utterance, commands, and non-verbal responses with the elevated group displaying less total utterances, less commands, and more non-verbal responses. Consistent with previous literature (e.g., Keller \& Carlson, 1974), these results suggest the importance of verbalizations in differentiating children with social anxiety from those without social anxiety. There were moderate sized differences between the follow-up groups on unsolicited conversation and freezing behavior, with the elevated group displaying less unsolicited conversation and more freezing behavior. As discussed above, making unsolicited conversation may be a more sophisticated social skill that is exhibited less frequently in preschool children, but signifies less inhibition when displayed. Similarly, freezing may be a more extreme reaction to social stress that is very salient when displayed. Those children who exhibited lower base-rate behaviors may go on to divergent developmental trajectories. Although this study was not powered to detect significant differences, the magnitude of these effects suggests that the specific verbal and non-verbal behaviors in preschool may relate to differing developmental trajectories for social anxiety.

\section{Limitations}

The above findings should be interpreted in light of several limitations. Foremost, this preliminary study consisted of a small number of participants and only a portion of those children were assessed at follow-up. The study was inadequately powered to detect the observed relations and therefore no definitive conclusions can be made. Although many attempts were made to make both assessment time-points as unobtrusive on the families as possible, only a relatively small number of children were recruited over a six month period. Although $57 \%$ of participants completed the four-year follow-up assessment, this left a small number of children to assess. 
Secondly, the study is limited by the restricted range of anxiety observed in the sample. Current estimations suggest that $1-2 \%$ of preschool-aged children experience problematic anxiety (Gadow, Sprafkin, \& Nolan, 2001). Children were observed in solitary behavior during unstructured play approximately $1 / 3$ of the time, but very few children exhibited extreme rates of solitary behavior. Similarly, very few parents endorsed high levels of social anxiety for their children. Approximately $1 \%$ of school-aged children (Costello et al., 2003) are estimated to suffer from high levels of social anxiety. In the current sample, only six children were indicated by at least one assessment measure as having problematic social anxiety follow-up. Similarly, at follow-up no parents or children reported the highest levels of social anxiety or the lowest social competence. This may be due to a Hawthorne Effect of parents and children wanting their child to appear less socially anxious and more socially competent. Alternatively, since parents were able to review the study procedures in the consent form prior to enrolling, it may be that parents of children with more inhibited children chose not to participate in an attempt to avoid potentially anxiety provoking interactions with strangers. It may also be that parents of extremely inhibited or anxious children chose not to enroll their children in preschool and waited until the compulsory age of school enrollment. Future studies may seek alternative methods of recruitment in other peer settings (e.g., dance classes, karate classes, playgrounds) in order to avoid a potential selection bias.

Lastly, highly salient, low base-rate behaviors (e.g., freezing, physical distancing) may not be readily captured in a brief observational period or in children with low levels of anxiety. Glennon and Weisz (1978) reported a similar difficulty and were not able to include low baserate behaviors, such as somatic complaints, hand movements toward the ears, crying, stuttering. Although these behaviors may not be relevant to anxiety, there is a stronger theoretical rationale for freezing and physical distancing as escape behaviors in the face of threat. Future research should examine these low base-rate behaviors across tasks of varying 
social and non-social threat intensity in preschool-aged children to determine their importance for early childhood anxiety.

\section{Implications and Future Directions}

The current findings have important implications for assessing risk factors for social anxiety in young children. Although the observational procedure assessed a group of behaviors displayed with a novel adult, the question remains whether children's behavior with a novel adult is related to problems with peers and anxiety in other contexts. The majority of the specific behaviors observed with the adult stranger did not relate to preschool social withdrawal from peers, preschool parent-report of social anxiety, or elementary school parent-report of social adjustment problems, social anxiety, or the child's report of social anxiety. Due to the low level of social anxiety observed in the current sample, this study may have observed behaviors indicative of normative stranger anxiety that is not impairing and remits in childhood. The current study established that the stranger-child task can be easily used within a school to assess behavior with a novel adult. The follow-up portion of the study revealed that verbal restraint behaviors in preschool may have a large effect on the development of social anxiety and poor social competence by elementary school, and may be an important indicator of risk.

Foremost, this study should be replicated with a larger sample of preschool children in order to test the hypotheses with adequate statistical power. To avoid many of limitations discussed above, future researchers may seek to oversample children who display anxious social withdrawal or social anxiety in preschool. Oversampling will protect against attrition and allow for an adequate follow-up sample of children who are observed as "at-risk" during preschool.

Future research should utilize signal detection theory to examine the levels of individual behaviors which indicate risk for anxiety in later childhood. Future longitudinal studies should examine, for example, how many nonverbal responses to direct questions suggest that the child may go on to develop social anxiety disorder. In order for the this observational procedure to be 
utilized as an early identification tool, the sensitivity and specificity of the codes should be empirically demarcated to predict problematic behavior.

Although the use of observational assessment was a significant strength of the current study and an important addition to the existing literature, future research should incorporate observational assessment at follow-up to determine whether the specific and global behaviors observed in preschool persist into childhood. Speech tasks and other socially challenging tasks have been used successfully with school-aged children (e.g., Beidel, Turner, Hamlin, \& Morris, 2000) and would provide an analogous follow-up assessment. In addition to observed solitary behavior and parent-report, future research could benefit from the inclusion of measures of peer acceptance and social status during elementary school (e.g., Booth-LaForce, Oh, Kennedy et al., 2012; Gazelle \& Ladd, 2003) to more broadly assess social adjustment.

Additionally, future research should extend the current findings to observe individual early childhood social skills displayed with peers in relation to social anxiety in elementary school. Although this study sought to extend previous research to examine solitary behavior with familiar peers, the specific and global observational behaviors should also be examined in relation to behavior with unfamiliar peers. Few studies have compared early childhood behavior with familiar peers and unfamiliar peers when identifying risk for anxiety. It may be important to determine whether continuity of socially withdrawn behavior across unfamiliar and familiar peers is more predictive of problematic social anxiety than social withdrawal only with unfamiliar peers.

Future research should extend the current findings to examine the effectiveness of using the stranger-child task and observational procedures within a clinic setting. As a primary aim of this study was to develop a transportable assessment procedure that can be used with adults in a classroom or in a clinical setting, it is important to examine the utility of this measure for children who display higher levels of anxiety to inform early interventions. 


\section{References}

Achenbach, T. M., \& Rescorla, L. A. (2001). Manual for the ASEBA School-Age Forms \& Profiles. Burlington, VT: University of Vermont, Research Center for Children, Youth, \& Families.

Achenbach, T. M., McConaughy, S. H., \& Howell, C. T. (1987). Child/adolescent behavioral and emotional problems: Implications of cross-informant correlations for situational specificity. Psychological Bulletin, 101, 213-232.

Ale, C. M., Chorney, D. C., Brice, C. S., \& Morris, T. M. (2010). Facial affect recognition and social anxiety in preschool children. Early Child Development and Care, 180, 1349-1359.

American Psychiatric Association. (2000). Diagnostic and statistical manual of mental disorders (Revised 4th ed.). Washington, DC: Author.

Asendorpf, J. B. (1991). Development of inhibited children's coping with unfamiliarity. Child Development, 62, 1460-1474.

Asendorpf, J. B. (1992). A Brunswikean approach to trait continuity: Application to shyness. Journal of Personality, 60, 53-77.

Asendorpf, J. B., Denissen, J. A., \& van Aken, M. A. G. (2008). Inhibited and aggressive preschool children at 23 years of age: Personality and social transitions into adulthood. Developmental Psychology, 44, 997-1011.

Asendorpf, J. B. \& van Aken, M. A. G. (1994). Traits and relationship status: Stranger versus peer group inhibition and test intelligence versus peer group competence as early predictors of later self-esteem. Child Development, 65, 1786-1798.

Beidel, D. C., Turner, S. M., \& Fink, C. M. (1996). Assessment of childhood social phobia: Construct, convergent, and discriminative validity of the Social Phobia and Anxiety Inventory for Children (SPAI-C). Psychological Assessment, 8, 235-240. 
Beidel, D. C., Turner, S. M., Hamlin, K., \& Morris, T. L. (2000). The Social Phobia Anxiety Inventory for Children (SPAI-C): External and discriminative validity. Behavior Therapy, 31, 75-87.

Beidel, D. C., Turner, S. M., \& Morris, T. L. (1995). A new inventory to assess childhood social phobia: The Social Phobia and Anxiety Inventory for Children. Psychological Assessment, 7, 73-79.

Bishop, G., Spence, S. H., \& McDonald, C. (2003). Can parents and teachers provide a reliable and valid report of behavioral inhibition? Child Development, 74, 1899-1917.

Booth LaForce, C. B., Oh, W., Root, A. E., Rubin, K. H., Rose-Krasnor, L., \& Laursen, B. (2012). Parent and peer links to trajectories of anxious withdrawal from grades 5 to 8 . Journal of Clinical Child and Adolescent Psychology, 41, 138-149.

Brozina, K. \& Abela, J. R. Z. (2006). Behavioural inhibition, anxious symptoms, and depressive symptoms: A short prospective examination of a diathesis-stress model. Behaviour Research and Therapy, 44, 1337-1346.

Buss, K. A. (2011). Which fearful toddlers should we worry about? Context, fear regulation, and anxiety risk. Developmental Psychology. Advance online publication. doi: 10.1037/a0023227

Buss, K. A., Davidson, R. J., Kalin, N. H., \& Goldsmith, H. H. (2004). Context-specific freezing and associated physiological reactivity as a dysregulated fear response. Developmental Psychology, 40, 583-594.

Chorney, D. B. (2009). Assessment of social anxiety in early childhood: Initial test construction and validation. Dissertation Abstracts International: Section B: The Sciences and Engineering, 69, 5015

Cicchetti, D. \& Wagner, S. (1990). Alternative assessment strategies for the evaluation of infants and toddlers: An organizational perspective. In S. J. Meisels \& J. P. Shonkoff 
(Eds.), Handbook of Early Childhood Intervention, (pp. 247-277). New York, NY: Cambridge University Press.

Cohen, J. (1988). Statistical Power Analysis for the Behavioral Sciences, $2^{\text {nd }}$ ed. Hillsdale, NJ: Lawrence Erlbaum.

Conroy, M. A. \& Brown, W. H. (2004). Early identification, prevention, and early intervention with young children at risk for emotional or behavioral disorders: Issues, trends, and a call for action. Behavioral Disorders, 29, 224-236.

Coplan, R. J. Prakash, K., O'Neil, K., \& Armer, M. (2004). Do you 'want' to play? Distinguishing between conflicted shyness and social disinterest in early childhood. Developmental Psychology, 40, 244-258.

Coplan, R. J., Rubin, K. H., Fox, N. A., Calkins, S. D., \& Stewart, S. L. (1994). Being alone, playing alone, and acting alone: Distinguishing among reticence and passive and active solitude. Child Development, 65, 129-137.

Costello, E. J., Egger, H. L., \& Angold, A. (2005). The developmental epidemiology of anxiety disorders: Phenomenology, prevalence, and comorbidity. Child and Adolescent Clinics of North America, 14, 631-648.

Costello, E. J., Mustillo, S., Erkanli, A., Keeler, G., \& Angold, A. (2003). Prevalence and development of psychiatric disorders in childhood and adolescence. Archives of General Psychiatry, 60, 837-844.

Denham, S. A. (1986). Social cognition, prosocial behavior, and emotion in preschoolers: Contextual validation. Child Development, 57, 194-201.

Denham, S. A. (2006a). Social-emotional competence as support for school readiness: What is it and how do we assess it? Early Education and Development, 17, 57-89.

Denham, S. A. (2006b). Emotional competence: Implications for social functioning. In J. L. Luby (Ed.), Handbook of Preschool Mental Health: Development, Disorders, and Treatment (pp. 23-44). New York, NY: Gilford Press. 
Dyson, M. W., Klein, D. N., Olino, T. M., Dougherty, L. R., \& Durbin, C. E. (2011). Social and non-social behavioral inhibition in preschool-age children: Differential associations with parent-reports of temperament and anxiety. Child Psychiatry and Human Development, 42, 390-405.

Edwards, S. L., Rapee, R. M., Kennedy, S. J., \& Spence, S. H. (2010). The assessment of anxiety symptoms in preschool-aged children: The Revised Preschool Anxiety Scale. Journal of Clinical Child \& Adolescent Psychology, 39, 400-409.

Engfer, A. (1993). Antecedents and consequences of shyness in boys and girls: A 6-year longitudinal study. In K. H. Rubin, \& J. B. Asendorpf (Eds.), Social withdrawal, inhibition, and shyness in childhood (pp. 177-187). Hillsdale, NJ: Lawrence Erlbaum.

Faul, F., Erdfelder, E., Buchner, A., \& Lang, A.-G. (2009). Statistical power analyses using G*Power 3.1: Tests for correlation and regression analyses. Behavior Research Methods, 41, 1149-1160.

Gadow, K. D., Sprafkin, J., \& Nolan, E. E. (2001). DSM-IV symptoms in community and clinic preschool children. Journal of the American Academy of Child and Adolescent Psychiatry, 40, 1383-1392.

Garcia Coll, C., Kagan, J., \& Reznick, J. S. (1984). Behavioral inhibition in young children. Child Development, 55, 1005-1019.

Gazelle, H. (2008). Behavioral profiles of anxious solitary children and heterogeneity in peer relations. Developmental Psychology, 44, 1604-1624.

Gazelle, H. (2010). Anxious solitude/withdrawal and anxiety disorders: Conceptualization, cooccurrence, and peer processes leading toward and away from disorders in childhood. In H. Gazelle \& K. H. Rubin (Eds.), Social anxiety in childhood: Bridging developmental and clinical perspectives. New Directions for Child and Adolescent Development, 127, 67-78. San Francisco: Jossey-Bass. 
Gazelle, H. \& Ladd, G. W. (2003). Anxious solitude and peer exclusion: A diathesis-stress model of internalizing trajectories in childhood. Child Development, 74, 257-278.

Gazelle, H. \& Rubin, K. H. (2010). Social anxiety in childhood: Bridging developmental and clinical perspectives. In H. Gazelle \& K. H. Rubin (Eds.), Social anxiety in childhood: Bridging developmental and clinical perspectives. New Directions for Child and Adolescent Development, 127, 1-16. San Francisco: Jossey-Bass.

Gazelle, H. \& Rudolph, K. D. (2004). Moving toward and away from the world: Social approach and avoidance trajectories in anxious solitary youth. Child Development, 75, 829-849.

Gredler, G. R. (1997). Issues in early childhood screening and assessment. Psychology in the Schools, 34, 99-106.

Grills, A. E., \& Ollendick, T. H. (2002). Issues in parent-child agreement: The case of structured diagnostic interviews. Clinical Child and Family Psychology Review, 5, 57-83.

Harter, S. \& Pike, R. (1984). Pictorial scale of perceived competence and social acceptance for young children. Child Development, 55, 1969-1982.

Hartmann, D. P. (1977). Considerations in the choice of interobserver reliability estimates. Journal of Applied Behavior Analysis, 10, 103-116.

Higa, C. K., Fernandez, S. N., Nakamura, B. J., Chorpita, B. F., \& Dalieden, E. L. (2006). Parental assessment of childhood social phobia: Psychometric properties of the Social Phobia and Anxiety Inventory for Children-Parent Report. Journal of Clinical Child and Adolescent Psychology, 35, 590-597.

Hirshfeld-Becker, D. R., Biederman, J., Henin, A., Faraone, S. V., Davis, S., Herrington, K, \& Rosenbaum, J. F. (2007). Behavioral inhibition in preschool children at risk is a specific predictor of middle childhood social anxiety: A five year follow-up. Journal of Developmental and Behavioral Pediatrics, 28, 225-233.

Jackson, D. A., Della-Piana, G. M., \& Sloane, H. N. (1975). How to establish a behavior observation system. Englewood Cliffs, NJ: Educational Technology. 
Kagan, J. (2001). Temperamental contributions to affective and behavioral profiles in childhood. In S. G. Holman \& P. M. DiBartolo (Eds.), From Social Anxiety to Social Phobia: Multiple Perspectives (pp. 216-234). Needham Heights, MA: Allyn and Bacon.

Kagan, J. (1992). Temperamental contributions to emotion and social behavior. In M.S. Clark (Ed.), Emotion and Social Behavior (pp. 99-118). Thousand Oaks, CA: Sage Publications.

Kagan, J., Reznick, J. S. \& Snidman, N. (1988). Biological bases of childhood shyness. Science, 240, 167-171.

Kagan, J. \& Snidman, N. (1991) Infant predictors of inhibited and uninhibited profiles. Psychological Science, 2, 40-44.

Kagan, J., Snidman, N., \& Arcus, D. (1998). Childhood derivatives of high and low reactivity. Child Development, 69, 1483-1493.

Kagan, J., Snidman, N., Kahn, V., \& Towsley, S. (2007). The preservation of two infant temperaments into adolescence. Monographs of the Social for Research in Child Development, 72, 1-75.

Kennedy, S. J., Rapee, R. M., \& Edwards, S. L. (2009). A selective intervention program for inhibited preschool-aged children of parents with an anxiety disorder: Effects on current anxiety disorders and temperament. Journal of the American Academy of Child and Adolescent Psychiatry, 48, 602-609.

Kessler, R. C., Berglund, P., Demler, O., Jin, R., Merikangas, K. R., \& Walters, E. E. (2005) Lifetime prevalence and age-of-onset distributions of DSM-IV disorders in the National Comorbidity Survey replication. Archives of General Psychiatry, 62, 593-602.

March, J. S. (1997). Distinguishing anxiety disorders psychometrically: Reply. Journal of the American Academy of Child and Adolescent Psychiatry, 36, 1646.

March, J. S., Parker, J. D. A., Sullivan, K., Stallings, P. \& Conners, C. K. (1997). The multidimensional anxiety scale for children (MASC): Factor structure, reliability, and 
validity. Journal of the American Academy of Child and Adolescent Psychiatry, 36, 554565.

March, J. S., Sullivan, K., \& Parker, J. (1999). Test-retest reliability of the multidimensional anxiety scale for children. Journal of Anxiety Disorders, 13, 349-358.

Meng, X, Robsenthal, R., \& Rubin, D. B. (1992). Comparing correlated correlation coefficients. Psychological Bulletin, 111, 172-175.

Mesman, J. \& Koot, H. M. (2001). Early preschool predictors of preadolescent internalizing and externalizing DSM-IV diagnoses. Journal of the American Academy of Child and Adolescent Psychiatry, 40, 1029-1036.

Moehler, E., Kagan, J., Oelkers-Ax, R., Brunner, R., Poustka, L, Haffner, J., \& Resch, F. (2008). Infant predictors of behavioural inhibition. British Journal of Developmental Psychology, 26, $145-150$.

Morris, T. L. (2004). Diagnosis of social anxiety disorder in children. In B. Bandelow \& D. J. Stein (Eds.), Social Anxiety Disorder (pp. 75-91). New York, NY: Marcel Dekker.

Morris, T. L., Hirshfeld-Becker, D. R., Henin, A., \& Storch, E. A. (2004). Developmentallysensitive assessment of social anxiety. Cognitive and Behavioral Practice, 11, 13-27.

Neal, J. A., Edelmann, R. J., \& Glachan, M. (2002). Behavioural inhibition and symptoms of anxiety and depression: Is there a specific relationship with social phobia? The British Journal of Clinical Psychology, 41, 361-374.

Park, S., Belsky, J., Putnam, S., \& Crnic, K. (1997). Infant emotionality, parenting, and 3-year inhibition: Exploring stability and lawful discontinuity in a male sample. Developmental Psychology, 33, 218-227.

Pfeifer, M., Goldsmith, H. H., Davidson, R. J., \& Rickman, M. (2002). Continuity and change in inhibited and uninhibited children. Child Development, 73, 1474-1485.

Piaget, J. (1965). The Moral Judgment of the Child. New York: The Free Press. 
Repp, A. C., Roberts, D. M., Slack, D. J., Repp, C. F., \& Berkler, M.S. (1976). A comparison of frequency, interval, and time-sampling methods of data collection. Journal of Applied Behavior Analysis, 9, 501-508.

Rezendes, M, Snidman, N., Kagan, J., \& Gibbons, J. (1993). Features of speech in inhibited and uninhibited children. In K. H. Rubin, \& J. B. Asendorpf (Eds.), Social withdrawal, inhibition, and shyness in childhood (pp. 177-187). Hillsdale, NJ: Lawrence Erlbaum.

Roberts, B. W., \& Caspi, A. (2003). The cumulative continuity model of personality development: Striking a balance between continuity and change in personality traits across the life course. In U. M. Staudinger, U. Lindenberger, U. M. Staudinger, U. Lindenberger (Eds.), Understanding human development: Dialogues with lifespan psychology (pp. 183-214). Dordrecht Netherlands: Kluwer Academic Publishers.

Rotenberg, K. J., Eisenberg, N., Cumming, C., Smith, A., Singh, M., \& Terlicher, E. (2003). The contributions of adults' non-verbal cues and children's shyness to the development of rapport between adults and preschool children. International Journal of Behavior Development, 27, 21-30.

Rubin, K. H. (1993). The waterloo longitudinal project: Correlates and consequences of social withdrawal from childhood to adolescence. In K. H. Rubin \& J. B. Asendorpf (Eds.), Social withdrawal, inhibition, and shyness in childhood (pp. 291-314). Hillsdale, NJ: Lawrence Erlbaum.

Rubin, K. H. \& Asendorpf, J. B. (1993). Social withdrawal, inhibition, and shyness in childhood: Conceptual and definitional issues. In K. H. Rubin \& J. B. Asendorpf (Eds.), Social withdrawal, inhibition, and shyness in childhood (pp. 3-17). Hillsdale, NJ: Lawrence Erlbaum.

Rubin, K.H., Bukowski, W. M., \& Parker, J. G. (2007). Peer interactions, relationships, and groups. N. Eisenberg (ed.), Handbook of Child Psychology, Volume 3: Social, Emotional, and Personality Development, pp. 571-645. 
Rubin, K. H., Burgess, K. B., \& Hastings, P. D. (2002). Stability and social-behavioral consequences of toddlers' inhibited temperament and parenting behaviors. Child Development, 73, 483-495.

Rubin, K. H., Hastings, P. D., Stewart, S. L., Henderson, H. A., \& Chen, X. (1997). The consistency and concomitants of inhibition: Some of the children, all of the time. Child Development, 68, 467-483.

Rubin, K. H., Hymel, S., \& Mills, R. S. L. (1989). Sociability and social withdrawal in childhood: Stability and outcomes. Journal of Personality, 57, 237-255.

Schmidt, L. A., Polak, C. P., \& Spooner, A. L. (2005). Biological and environmental contributions to childhood shyness: A diathesis-stress model. In W. R. Crozier \& L. E. Alden (Eds.), The essential handbook of social anxiety for clinicians (pp. 33-55). United Kingdom: Wiley.

Schneider, B. H., Younger, A. J., Smith, T., \& Freeman, P. (1998). A longitudinal exploration of the cross-contextual stability of social withdrawal in early adolescence. Journal of Early Adolescence, 18, $374-396$.

Schwartz, C. E., Kunwar, P. S., Greve, D. N, Moran, L. R. Viner, J. C... Wallace, S. R. (2010). Structural differences in adult orbital and ventromedial prefrontal cortex predicted by infant temperament at 4 months of age. Archives of General Psychiatry, 67, 78-84.

Schwartz, C. E., Snidman, N. \& Kagan, J. (1999). Adolescent social anxiety as an outcome of inhibited temperament in childhood. Journal of the American Academy of Child and Adolescent Psychiatry, 38, 1008-1015.

Shrout, P. E. \& Fleiss, J. L. (1979). Intraclass correlations: Uses in assessing rater reliability. Psychological Bulletin, 86, 420-428.

Spence, S. H. (1998). A measure of anxiety symptoms among children. Behaviour Research and Therapy, 36, 545-566. 
Spence, S. H., Donovan, C., \& Brechman-Toussaint, M. (1999). Social skills, social outcomes, and cognitive features of childhood social phobia. Journal of Abnormal Psychology, 108, 211-222.

Spence, S. H., Rapee, R., McDonald, C., \& Ingram, M. (2001). The structure of anxiety symptoms among preschoolers. Behaviour Research and Therapy, 39, 1293-1316.

Sterba, S., Egger, H. L., \& Angold, A. (2007). Diagnostic specificity and nonspecificity in the dimensions of preschool psychopathology. Journal of Child Psychology and Psychiatry, 48, 1005-1013.

Turner, S. M., Beidel, D. C., \& Wolff, P. L. (1996). Is behavioral inhibition related to the anxiety disorders? Clinical Psychology Review, 16, 157-172.

Waters, E. \& Sroufe, L. A. (1983). Social competence as a developmental construct. Developmental Review, 3, 79-97.

Younger, A., Gentile, C., \& Burgess, K. (1993). Children's perceptions of social withdrawal: Changes across age. In K. H. Rubin, \& J. B. Asendorpf (Eds.), Social withdrawal, inhibition, and shyness in childhood (pp. 215-235). Hillsdale, NJ: Lawrence Erlbaum. 
Table 1. Descriptives for Preschool-aged Assessments and Follow-up Assessments.

\begin{tabular}{|c|c|c|c|c|}
\hline & $\mathrm{M}$ & SD & Minimum & Maximum \\
\hline Shyness & 1.71 & 1.24 & 0.00 & 4.00 \\
\hline Volume of Speech & 2.39 & .99 & 0.00 & 4.00 \\
\hline Postural Rigidity & 2.14 & .85 & 0.00 & 4.00 \\
\hline Total utterances & 13.63 & 6.45 & 5.00 & 26.00 \\
\hline Commands (\%) & 1.50 & 4.30 & .00 & 16.67 \\
\hline Questions (\%) & 7.87 & 12.99 & .00 & 46.67 \\
\hline Unsolicited Conversation (\%) & 35.36 & 32.00 & .00 & 94.44 \\
\hline Direct Response & 55.27 & 40.23 & .00 & 100.00 \\
\hline Gaze Aversion & 10.44 & 5.64 & .00 & 18.00 \\
\hline Non-verbal Response & 1.85 & 2.13 & .00 & 6.00 \\
\hline Physical Distancing & .15 & .46 & .00 & 2.00 \\
\hline Freeze & .78 & 2.02 & .00 & 10.00 \\
\hline Smile & 1.22 & 2.06 & .00 & 7.00 \\
\hline SPAS $_{\text {soc }}$ (parent report) & 4.09 & 3.00 & .00 & 10.00 \\
\hline Solitary Behavior (observation, \%) & 33.04 & 27.64 & .00 & 99.00 \\
\hline SPAIC (parent report) & 6.87 & 6.12 & .00 & 18.03 \\
\hline CBCL Social Competence (parent report) & 10.42 & 2.57 & 5.00 & 14.00 \\
\hline SPAIC-10 (child self-report) & 2.92 & 2.39 & .00 & 7.62 \\
\hline
\end{tabular}


Table 2. Correlations of Preschool Observational Codes

\begin{tabular}{|c|c|c|c|c|c|c|c|c|c|c|c|c|}
\hline & 1. & 2. & 3. & 4. & 5. & 6. & 7. & 8. & 9. & 10. & 11. & 12. \\
\hline 1. Shyness & - & $.72^{\star \star}$ & $.62^{\star \star}$ & $-.39^{*}$ & $-.80^{\star \star}$ & $-.86^{\star \star}$ & $.93^{\star \star}$ & $.61^{\star \star}$ & $.74^{\star \star}$ & .01 & $.43^{\star}$ & $-.38^{*}$ \\
\hline 2. Vol. Speech & & - & $.76^{\star *}$ & $-.29^{* *}$ & $-.65^{\star *}$ & $-.66^{* *}$ & $.71^{* *}$ & $.42^{*}$ & $.80^{* *}$ & .00 & $.50^{* *}$ & -.34 \\
\hline 3. Postural Rigidity & & & - & -.23 & $-.63^{\star \star}$ & $-.58^{* *}$ & $.64^{* \star}$ & $.44^{*}$ & $.70^{\star *}$ & -.03 & $.42^{*}$ & -.37 \\
\hline 4. Commands & & & & - & $.46^{*}$ & .33 & -.38 & -.20 & $-.42^{*}$ & -.15 & -.27 & $.48^{*}$ \\
\hline 5. Questions & & & & & - & $.62^{*}$ & $-.78^{\star \star}$ & $-.51^{\star *}$ & $-.59^{* \star}$ & .01 & $-.51^{\star \star}$ & $.39^{*}$ \\
\hline 6. Unsolicited Conv. & & & & & & - & $-.93^{* *}$ & $-.54^{\star *}$ & $-.70^{* *}$ & -.21 & $-.38^{* *}$ & .36 \\
\hline 7. Direct Response & & & & & & & - & $.55^{\star *}$ & $.74^{\star *}$ & .06 & $.42^{*}$ & $-.39^{*}$ \\
\hline 8. Gaze Aversion & & & & & & & & - & $.40^{*}$ & .10 & -.11 & $-.58^{* *}$ \\
\hline 9. Non-verbal Resp. & & & & & & & & & - & .03 & $.41^{*}$ & -.27 \\
\hline 10. Phys. Distancing & & & & & & & & & & 一 & -.23 & -.32 \\
\hline 11. Freeze & & & & & & & & & & & - & -.11 \\
\hline 12. Smile & & & & & & & & & & & & - \\
\hline
\end{tabular}

${ }^{* *} p<.01,{ }^{*} p<.05$ 
Table 3. Regression Analysis Summary for Global Behavioral Observations Relating to Solitary Behavior during Unstructured Play

\begin{tabular}{lllll} 
& $B$ & $S E B$ & $\beta$ & .04 \\
\hline Shyness & .91 & 6.01 & .21 & .22 \\
\hline Volume of Speech & 6.15 & 9.28 & .30 & .24 \\
\hline Postural Rigidity & 9.83 & 9.09 & & .24 \\
\hline
\end{tabular}

$F(3,23)=2.73, p=.07 ; R^{2}=.26 ;$ Collinearity tolerance $=.40-.60$ (within acceptable parameters) 
Table 4. Correlations of Preschool Micro-codes and Tests of Dependent Correlations among Preschool Other Informant Assessments.

\begin{tabular}{lcccc}
\hline & Solitary Behavior (obs) & Social Anxiety (parent) & $z$ & .20 \\
\hline Commands & -.21 & -.11 & .05 & .84 \\
\hline Questions & -.06 & -.01 & -.46 & .96 \\
\hline Unsolicited Conv. & -.31 & -.19 & .35 & .65 \\
\hline Direct Response & .21 & .17 & .00 & .72 \\
\hline Gaze Aversion & .23 & .22 & .61 & 1.00 \\
\hline Non-verbal Response & .37 & .26 & -.53 & .54 \\
\hline Physical Distancing & .07 & -.05 & 1.41 & .59 \\
\hline Freeze & .21 & -.15 & -1.65 & .10 \\
\hline Smile & -.31 & .12 & \\
\hline
\end{tabular}


Table 5. Correlations between Preschool Observational Micro-Codes and Follow-up Assessments.

\begin{tabular}{lccc}
\hline & \multicolumn{3}{c}{ Follow-up Assessments } \\
\cline { 2 - 4 } Preschool Micro-Codes: & Social Anxiety (parent) & Social Competence (parent) & Social Anxiety (child) \\
\hline Total Utterances & & & .06 \\
\hline Commands & -.44 & -.36 & -.37 \\
\hline Questions & -.42 & -.20 & .09 \\
\hline Unsolicited Conv. & -.26 & -.37 & .30 \\
\hline Direct Response & -.08 & $-.53^{*}$ & -.19 \\
\hline Gaze Aversion & .21 & $.57^{*}$ & .17 \\
\hline Non-verbal Resp. & .21 & .20 & .01 \\
\hline Freeze & .40 & .41 & -.17 \\
\hline Smile & -.07 & .42 & .06 \\
\hline
\end{tabular}

Note: Physical distancing behaviors did not occur in the follow-up sample; Social Anxiety (parent) = P-SPAIC; Social Competence (parent) = $\mathrm{CBCL}$ Social Competence Scale score; Social Anxiety (child) = SPAIC-10

${ }^{*} p<.05,{ }^{* *} p<.01$ 
Table 6. Results of ANOVA tests comparing Preschool Observational Micro-Codes for Children with and without Elevated Social Anxiety at Follow-up.

\begin{tabular}{lcccc}
\hline & \multicolumn{2}{c}{$M(S D)$} & $F$ & $p$ \\
\hline $\begin{array}{l}\text { Preschool Micro- } \\
\text { Observations: }\end{array}$ & $\begin{array}{c}\text { Follow-up Elevation } \\
\text { Group }(n=6)\end{array}$ & $\begin{array}{c}\text { Follow-up No } \\
\text { Elevation Group }(n=9)\end{array}$ & & n.s. \\
\hline Total Utterances & $10.67(6.53)$ & $13.89(5.53)$ & .96 & .53 \\
\hline Commands & $.00(.00)$ & $.44(1.33)$ & .65 & n.s. \\
\hline Questions & $.67(1.03)$ & $.89(1.54)$ & .10 & n.s. \\
\hline Unsolicited Conv. & $5.17(7.73)$ & $7.11(6.97)$ & .26 & n.s. \\
\hline Direct Response & $4.83(3.19)$ & $5.44(3.21)$ & .13 & n.s. \\
\hline Gaze Aversion & $12.33(3.93)$ & $11.56(6.17)$ & .07 & n.s. \\
\hline Non-verbal Resp. & $3.00(1.67)$ & $1.67(2.18)$ & 1.60 & n.s. \\
\hline Freeze & $.50(.55)$ & $1.22(3.31)$ & .27 & n.s. \\
\hline Smile & $1.00(2.00)$ & $.89(1.27)$ & .01 & n.s. \\
\hline
\end{tabular}

Note: Physical distancing was not observed in the follow-up sample. 


\section{Appendix A.}

\section{Stranger-child Microanalytic Coding System}

\begin{tabular}{|c|c|c|}
\hline & Behavioral code & $\underline{\text { Criteria }}$ \\
\hline \multirow[t]{5}{*}{ Non-verbal } & Eye gaze aversion & $\begin{array}{l}\text { The child's head and eyes are directed away from the stranger (e.g., looking at toy, } \\
\text { look at camera, look at other). }\end{array}$ \\
\hline & $\begin{array}{l}\text { Non-verbal response } \\
\text { to direct question }\end{array}$ & $\begin{array}{l}\text { Behavior directed toward the stranger within } 3 \text { seconds of a question (e.g., shrug, } \\
\text { shake, nod, hand gesture). }\end{array}$ \\
\hline & Physical distancing & $\begin{array}{l}\text { The child moves his or her body in the opposite direction of the stranger. This can be } \\
\text { indicated by the child's bottom moving, but also be noticeable leaning away from the } \\
\text { stranger. }\end{array}$ \\
\hline & Freezing & $\begin{array}{l}\text { The child displays an absence of body movements for the majority of the } \\
\text { observational interval. }\end{array}$ \\
\hline & Smiling & The child's mouth is curved in a U-shape and lasting a minimum 2 seconds. \\
\hline \multirow[t]{4}{*}{ Verbal } & Command & The child makes a directive command toward the stranger. E.g., look at this. \\
\hline & Question & $\begin{array}{l}\text { The child directs a question toward the stranger. For example, What's your name? or } \\
\text { What are you doing? This can be denoted by the use of question words, but also by a } \\
\text { marked up inflection at the end of an utterance. }\end{array}$ \\
\hline & $\begin{array}{l}\text { Unsolicited } \\
\text { conversation }\end{array}$ & $\begin{array}{l}\text { The child makes a statement which does not relate to the stranger's questions or to } \\
\text { the task in general. E.g., I was Sponge Bob for Halloween. Note: A random or } \\
\text { unsolicited comment in the form of a question or command should not be coded as } \\
\text { "unsolicited conversation." }\end{array}$ \\
\hline & Direct response & $\begin{array}{l}\text { Complies with stranger's question through direct verbal answer. Note: Elaboration } \\
\text { onto a non-directly related topic should be coded as "unsolicited conversation." }\end{array}$ \\
\hline
\end{tabular}




\section{Appendix B.}

\section{Stranger-child Global Coding}

Participant \#

Coder:

Date:

$1^{\text {st }}$ Viewing: Global Codes

\begin{tabular}{cll} 
Shyness & \\
\hline $\mathbf{1}$ & Very outgoing & Initiates contact quickly; appears confident when talking to stranger; talks a lot; requires no prompting. \\
\hline $\mathbf{2}$ & Outgoing & $\begin{array}{l}\text { Somewhat slow to speak to stranger (>60 secs); appears confident when talking to stranger; requires } \\
\text { occasional prompting. }\end{array}$ \\
\hline $\mathbf{3}$ & Average & $\begin{array}{l}\text { Slow to speak to stranger (>120 secs); appears comfortable when talking to stranger, but requires } \\
\text { prompting; does not say too much. }\end{array}$ \\
\hline $\mathbf{4}$ & Very Shy & Does not initiate contact; one/two word answers or nods/shakes of head. \\
\hline Volume of speech & Does not talk at all; frequent, long gazes at stranger; fearful facial expression; might cry. \\
\hline $\mathbf{0}$ & Very loud & Very loud speech, at times yelling \\
\hline $\mathbf{1}$ & Loud & Clear speech, at times getting loud \\
\hline $\mathbf{2}$ & Average & An appropriate "indoor voice." Approximately the same loudness as the stranger. \\
\hline $\mathbf{3}$ & Quiet & Small voice, whispering, at times difficult to hear \\
\hline $\mathbf{4}$ & Very quiet & Predominantly inaudible \\
\hline Postural rigidity & \\
\hline $\mathbf{0}$ & Limp & Moving around frequently with ease. Often becoming floppy. \\
\hline $\mathbf{1}$ & Relaxed & Fluid movements and relaxed posture. \\
\hline $\mathbf{2}$ & Average & Appears comfortable. Posture is unremarkable. \\
\hline $\mathbf{3}$ & Stiff & Sitting relatively still, with purposeful movements. \\
\hline $\mathbf{4}$ & Rigid & Very rigid movement or posture. If movements occur, they are stilted. \\
\hline
\end{tabular}




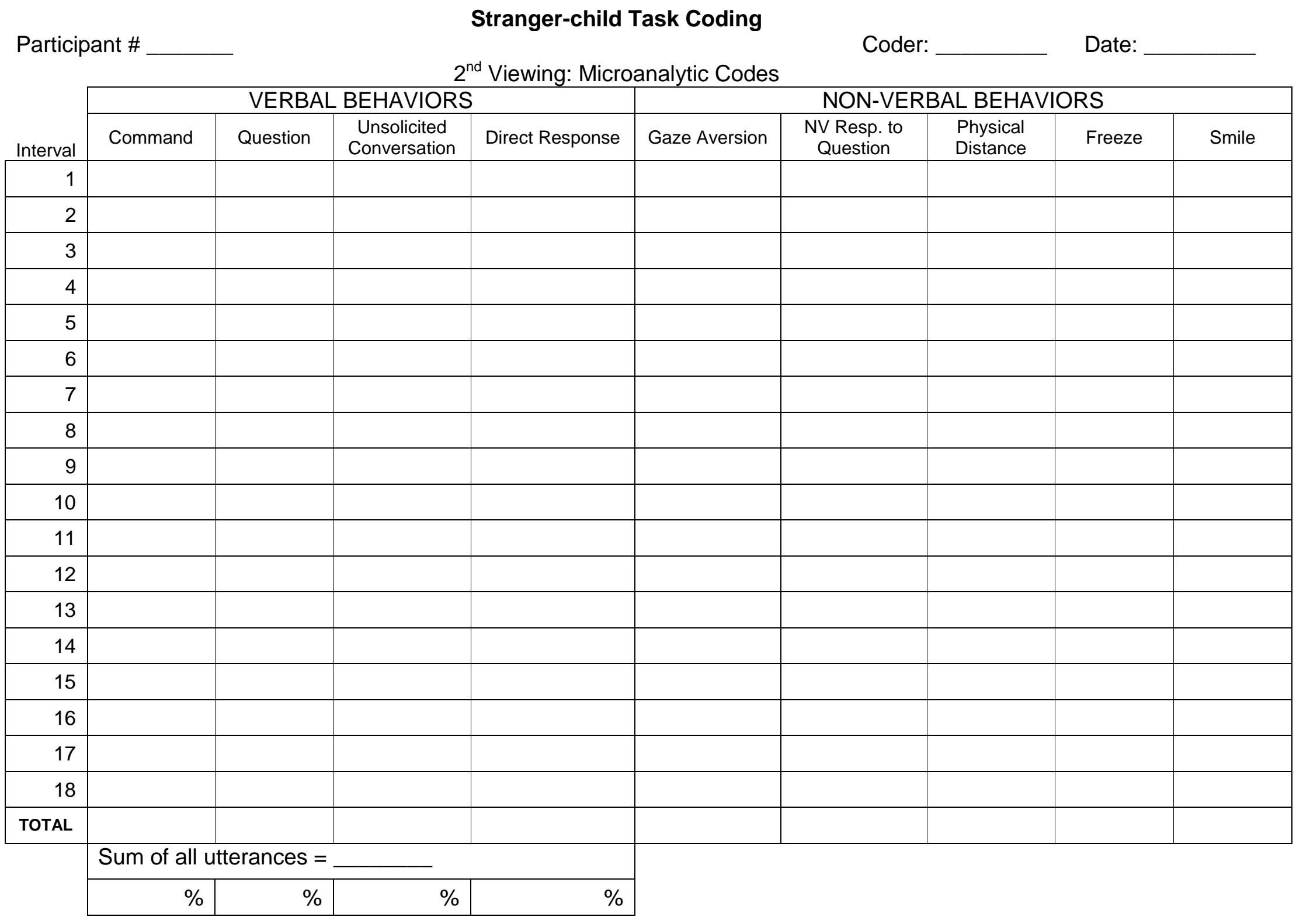


Appendix C.

Demographic Questionnaire

\section{ABOUT YOU AND YOUR FAMILY}

Your name: Your child's name:

Your age:

Child's Age:

Your relationship to the child: Child's Sex: Boy__ Girl

Your ethnicity:

Caucasian

African American

Hispanic

Asian American

Native American

Other:
Your child's ethnicity:

Caucasian

African American

Hispanic

Asian American

Native American

Other:

Occupation: Please provide your job position or title, NOT the name of your employer. For example, if you are a teacher at Morgantown High school, please state "high school teacher." If you are retired, please state "retired" as well as your prior occupation. If you do not work outside the home, please state "stay at home parent" or "unemployed."

What is your occupation?

$$
\text { (please be specific) }
$$

Highest Level of Education Completed:

Did not complete high school

High School

Some College

College Degree

Graduate Degree

Please complete the following information about your spouse (if applicable):

Your spouse's age:

Your spouse's occupation:

Highest level of education completed by your spouse: Your spouse's ethnicity:

Did not complete high school

High School

Some College

College Degree

Graduate Degree

Your spouse's ethnicity:

Caucasian

African American

Hispanic

Asian American

Native American

Other: 